\title{
The relationship between dietary intake and the six dimensions of wellness in older adults
}

\author{
Angela G. Dalton · John V. Logomarsino
}

\begin{abstract}
The purpose of this review was to provide older adults with a clear idea of how dietary patterns can improve wellness, and how wellness can improve dietary patterns. A large portion of the US population is advancing in age and there is potential for an associated plateau or decline in wellness with age. Therefore, strategies to improve personal wellness and dietary patterns should be considered. This review examined the associations between dietary intake and each of the six dimensions of wellness, as defined by the National Wellness Institute, in adults 50 years old or older. A cause-and-effect relationship of specific dietary patterns on intellectual, occupational, emotional, and physical wellness was explored. In addition, studies regarding the cause-and-effect relationship of spiritual and social wellness on dietary choice were evaluated. Essentially, dietary intake and wellness were closely related. The research suggests that intellectual, occupational, emotional, and physical wellness may improve with dietary changes. Nutrition status may improve with enrichment in social and spiritual wellness. Overall, older adults can enhance wellness by following a few simple guidelines: increase the intake of plantbased foods, avoid processed foods, engage in a spiritual community that encourages healthy lifestyles, and seek dining companions in order to increase caloric intake.
\end{abstract}

Keywords: diet, nutrition, wellness, older adult, aged

\section{Introduction}

A person's dietary pattern influences physical health, disease state, and mortality (Ruel et al., 2013; Knoops et al., 2006; Lagiou et al., 2006). This paper will investigate how dietary patterns influence wellness. Personal wellness is "an active process through which people become aware of, and make choices toward, a more successful existence" (The National Wellness Institute, n.d.). A six-dimension approach to wellness, comprising emotional, occupational, physical, social, intellectual, and spiritual wellness, is used by The National Wellness Institute (see Figure 1 below). This provides a holistic approach, based on the interconnectedness of all six dimensions. Wellbeing, on the other hand, has been described as what makes a life go well for someone (International Journal of Wellbeing, n.d.), or the state of being happy, healthy, or successful (Merriam-Webster, n.d.). Wellness can be thought of as the active and intentional process that leads to a state of wellbeing. Therefore, although the words "wellbeing" and "wellness" are often used interchangeably, this review will speak more toward improving wellness rather than wellbeing, with the assumption that improving each of the six dimensions of wellness will result in a state of wellbeing. 
Figure 1. The six dimensions of wellness (The National Institute of Wellness, n.d.)

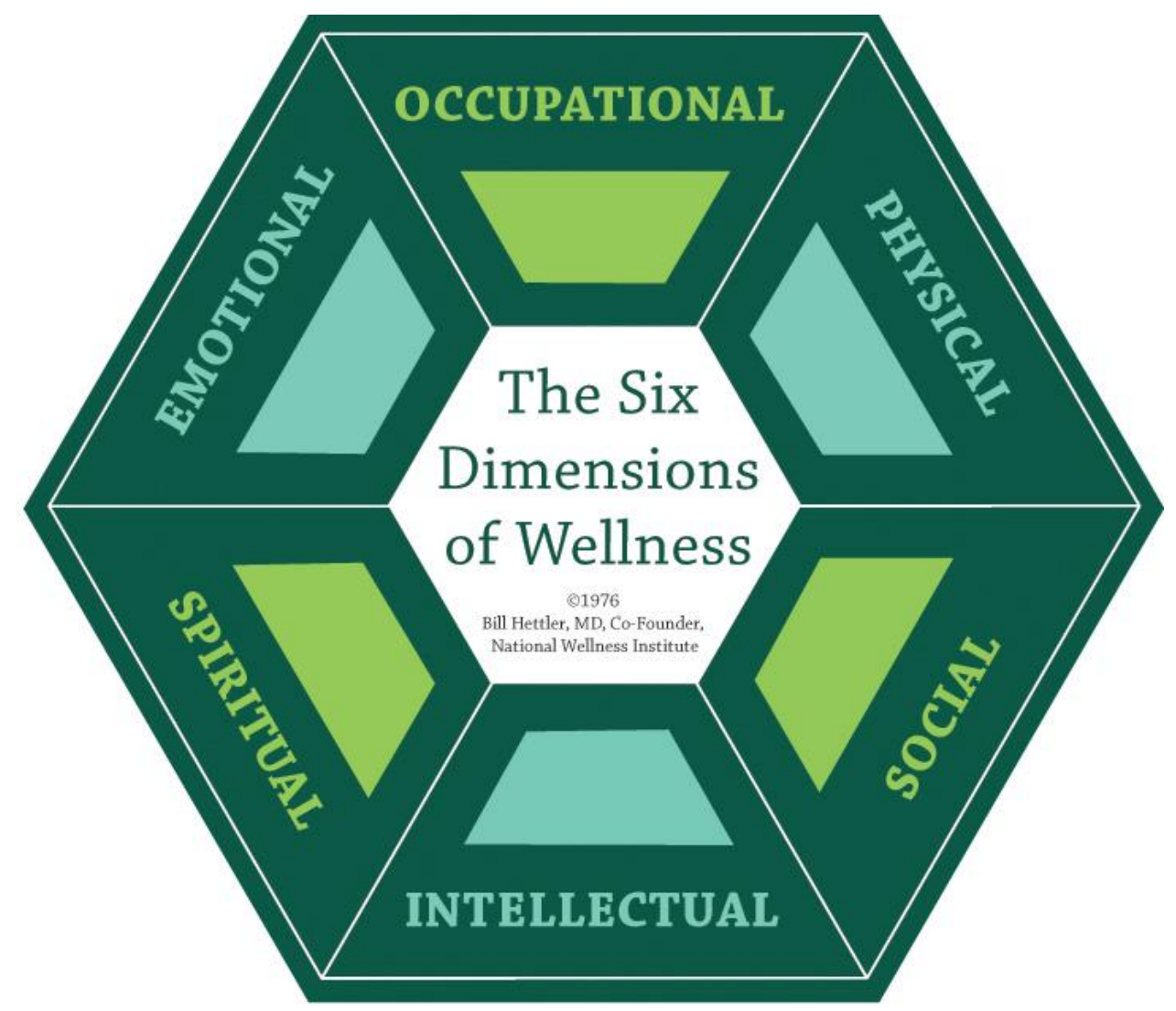

It has been suggested that wellbeing increases with age, but may peak in the $7^{\text {th }}$ decade of life (Carstensen et al., 2011). In 2010, nearly 99 million Americans were 50 years old or older (U.S. Department of Commerce, 2010); 40 million of these were 65 years old or older (Federal Interagency Forum on Aging-Related Statistics, 2012). This review examines the cause-and-effect relationship of specific nutrients on intellectual, occupational, emotional, and physical wellness. Furthermore, this review examines the cause-and-effect relationship of spiritual and social wellness as each pertains to dietary intake. Search methods included a PubMed database search for each wellness dimension, including wellness and dietary terms for each. Studies with adults over the age of 50 and published in the last 20 years were the primary focus.

\section{Review of the literature}

\subsection{Intellectual wellness}

Intellectual wellness recognizes mental activity and creativity, with a focus on problem solving, creativity, and learning (Hettler, 1976). Age-related memory loss is common (Federal Interagency Forum on Aging-Related Statistics, 2006), and Alzheimer's disease was among the top five leading causes of death for older adults in 2009 (Federal Interagency Forum on Aging-Related Statistics, 2012). Eating to protect against memory loss will be addressed here (see Appendix, Table A for detailed descriptions of research).

Memory problems have been reported more frequently in older subjects compared to younger (Small et al., 2013). Fruit, vegetable, and antioxidant consumption might protect against these problems. In one study of over 18,000 adults, healthy eating and fruit and vegetable consumption were associated with improved memory in all ages. There was a $26 \%$ higher 
likelihood of memory problems in those who did not report healthy eating when compared to those who did (Small et al., 2013). Furthermore, biomarkers of oxidative stress were negatively associated with global cognitive function, including memory (measured by Mini-Mental State Examination, MMSE (Folstein, Folstein, \& McHugh, 1975)). Antioxidants lycopene and alphatocopherol were positively associated with cognition (Polidori et al., 2009). Those consuming five or more servings of produce per day demonstrated higher antioxidant micronutrients, lower indicators of oxidative stress, and better cognitive functioning compared to those consuming only one serving of produce per day (Polidori et al., 2009).

Antioxidants were further examined in adults with high cardiovascular disease (CVD) risk. Memory function and global cognition were improved with higher intakes of total and virginonly olive oils, coffee, walnuts, and wine (Valls-Pedret et al., 2012). Another observational study of nearly 7,000 older adults found similar results with antioxidant-rich olive oil. Intensive olive oil use was associated with a reduction in both verbal fluency decline and visual memory decline (Berr et al., 2009). Similarly, in adults with more severe mental decline there was a $50 \%$ reduced risk for those with a higher concentration of total tocopherols, tocotrienols, or total vitamin E when compared to those with lower plasma levels (Mangialasche et al., 2010).

The relationship between antioxidant status and cognition has been examined via randomized controlled trials (RCTs). Both grape (Krikorian, Nash, Shidler, Shukitt-Hale, \& Joseph, 2010) and pomegranate (Bookheimer et al., 2013) juice were studied among small samplings (28 and 12 subjects, respectively) of older adults with mild memory complaints. Grape juice consumption improved verbal learning and retention from baseline to 12-week follow up compared to controls (Krikorian et al., 2010). Consuming pomegranate juice for 28 days while consuming an otherwise low-polyphenol diet resulted in improved total recall, long-term retrieval scores, and increased brain activity compared to controls (Bookheimer et al., 2013). Therefore, both observational studies and controlled interventions demonstrate that antioxidants may protect against memory loss, thus improving intellectual wellness.

Observational studies have examined dietary constituents other than antioxidants and their association with cognition. One study found that adjusted means for both fatty fish and marine omega-3 polyunsaturated fatty acids (PUFA) (docosahexaenoic acid (DHA) and eicosapentaenoic acid (EPA)) were higher in subjects with normal cognition compared to those with impaired cognition (Kalmijn et al., 2004). Higher dietary cholesterol intake was positively and significantly associated with risk for impaired memory and flexibility. However, cognitive function and the overall intake of total PUFA, linoleic acid, alpha-linoleic acid, and monounsaturated fatty acids (MUFA) demonstrated no relationship (Kalmijn et al., 2004). In a study of 65-90 year olds, intake of overall food, fish and alcohol (moderate) were higher and "various" foods, which included chocolates and sweets, were lower in those with satisfactory MMSE scores (Requejo et al., 2003). Another study comparing a whole foods dietary pattern with a processed foods dietary pattern found that the processed foods were associated with poorer memory. The whole-food pattern was not associated with cognition (Torres et al., 2012). Micronutrients associated with improved cognition included thiamin, folate, and vitamin C (Requejo et al., 2003). Higher cereal and meat intakes (Valls-Pedret et al., 2012) and saturated fat, MUFA and cholesterol (Requejo et al., 2003) were all associated with poorer cognition. Similarly, confusion levels were higher in omnivores than vegetarians among 39 healthy subjects (Beezhold \& Johnston, 2012).

Finally, following the Dietary Guidelines for Americans may also protect intellectual wellness. For example, a dietary pattern following the Dietary Guidelines for Americans (which emphasize nuts, fatty fish, low-fat dairy products, whole grains and fruits and vegetables) was 
associated with lower levels of cognitive decline in older adults (Wengreen, Neilson, Munger, \& Corcoran, 2009).

Based on the evidence, intellectual wellness by way of memory and cognition may be improved via consumption of antioxidants (specifically lycopene and alpha-tocopherols), PUFA and fish/fish oils. Most of this information was based on observational studies, and therefore cannot prove causation. Further research should include RCTs examining MUFA and intellectual wellness since some results here were conflicting (Berr et al., 2009; Kalmijin et al., 2004). While RCTs are the gold standard for quality research, there were only two RCTs provided here, and both consisted of small sample sizes. Overall, a dietary pattern of whole foods such as coffee, alcohol (moderate), walnuts, fruits, vegetables, and fatty fish may improve intellectual wellness. Conversely, consuming processed foods such as sweets, processed animal products, and cereals may impair cognition and memory, resulting in poorer intellectual wellness.

\subsection{Occupational wellness}

Occupational wellness is related to a person's attitude about work. Choice of profession, job satisfaction, career goals, and personal work performance comprise occupational wellness (Hettler, 1976). In 2011 the labor force included 75\% of men and 65\% of women aged 55-61, and $53 \%$ of men and $45 \%$ of women aged 62-64 (Federal Interagency Forum on Aging-Related Statistics, 2012). Excessive daytime sleepiness may contribute to reduced productivity and poorer mental health in the workplace (Liviya Ng, Freak-Poli, \& Peeters, 2014), therefore diminishing personal work performance and occupational wellness. Given the sedentary nature of many jobs, addressing alertness and wakefulness as components of job performance may be appropriate for many older adults who are still in the work force (see Appendix, Table B for a detailed description of research).

Macronutrient content of meals and the relation to work performance has been examined in RCTs. In one study examining the correlation of high-fat, low carbohydrate versus low-fat, high carbohydrate meals with daytime sleepiness, feelings of fatigue increased while vigor and energy decreased throughout the day. Regardless of meal content, subjects felt less vigorous 45 minutes after ingestion than they did prior to eating. Subjects demonstrated poorer performance 45 minutes after a low-fat first test meal compared to a high-fat first test meal, indicating that fat content of meals may affect performance (Wells, Read, Idzikowski, \& Jones, 1998). Meals consumed between 11am and 3pm, regardless of macronutrient content, resulted in the highest rate of postprandial sleepiness (Wells et al., 1998). Therefore, sleepiness might be more likely after any meal, especially if eaten between the hours of $11 \mathrm{am}$ and $3 \mathrm{pm}$, regardless of macronutrient content (Wells et al., 1998). In another study of 11 male truck drivers there was no difference demonstrated between macronutrient content of meals (high fat vs. low fat) and wakefulness (Landstrom, Knutsson, \& Lennernas, 2000).

It is often assumed that a "heavy" meal equates to lower levels of alertness. Effects of energy and volume on satiation and alertness were examined in 10 healthy adults aged 18-64 years (Landstrom, Knutsson, Lennernas, \& Stenudd, 2001). Sleep- and food-deprived subjects reported equally reduced subjective drowsiness immediately after consuming all meals, regardless of energy or water volume content. Sleepiness ratings followed a bell-shaped curve - more drowsiness before a meal, less drowsiness while eating, and more drowsiness again after the meal. While drowsiness was reportedly lower during consumption, this may be due to the physical action of eating rather than the nutrients themselves (Landstrom et al., 2001).

In a large observational study of post-menopausal women total fat, calories, saturated fat, MUFA, and trans fat were all associated with subjective napping, a potential indicator of daytime 
sleepiness (Grandner, Kripke, Naidoo, \& Langer, 2010). A number of these nutrients may be linked to animal fats (fatty meats, dairy products). Conversely, objective sleep duration was negatively associated with many of these same nutrients. Hence, while consumption of most fats might cause subjective sleepiness, fat intake might actually result in less overall sleep time (Grandner et al., 2001). While these RCTs and observational studies examined meal content, they did not examine the absence of a meal and the subsequent effect on sleepiness.

Missing a meal may occur from time to time during a busy workday. One controlled study of younger adults demonstrated the effects of alertness during eight hours of sedentary work when missing a meal (Neely, Landstrom, \& Bystrom, 2004). Subjective scores for both lack of energy and lack of motivation were lower at $4 \mathrm{pm}$ on days when a meal was missed, indicating that subjects felt more energetic and motivated on days they consumed both breakfast and lunch (Neely et al., 2004). Results from this study indicate that missing at least one meal during a sedentary workday might result in increased feelings of sleepiness, and decreased motivation. It must be noted that this last study (Neely et al., 2004) included a significantly younger population than the target population of this paper. There was a surprising lack of research for alertness/job performance and diet among older adults. Given the number of older adults in the workforce, this gap in research is alarming and should be addressed.

Results from the few studies presented here indicate that any meal may reduce alertness and increase sleepiness after ingestion. Foods higher in saturated and trans fats and MUFA resulted in subjects feeling sleepier during the day. During the workday, older adults might improve occupational wellness by avoiding high-fat meals. As many of the nutrients associated with increased subjective daytime sleepiness are found in high-fat animal products and also processed foods, these foods should be avoided during the workday. However, since low-fat meals were associated with poorer performance (Wells et al., 1998), it might be beneficial to consume PUFA as a dietary fat source during the workday. Older adults might also improve occupational wellness by consuming meals prior to $11 \mathrm{am}$ and after $3 \mathrm{pm}$. Guidelines for intellectual wellness can also apply to occupational wellness, since memory and cognition will play a role in most jobs.

\subsection{Emotional Wellness}

Emotional wellness relates to one's feelings and includes the degree to which a person feels positively and enthusiastically about life (Hettler, 1976). When stress levels exceed what most would consider normal, personal wellness can be negatively affected. Anxiety is an emotion characterized by feelings of tension, worried thoughts, and physical changes like increased blood pressure (American Psychological Association, 2014). While stress can affect the way people eat, especially in emotional eaters (Oliver, Wardle, \& Gibson, 2000), it is unclear what dietary habits could affect stress levels. Dietary intake and associations with stress and anxiety will be addressed here (see Appendix, Table $C$ for a detailed description of research).

The Mediterranean dietary pattern (primarily comprising non-starchy fresh produce, fish, nuts, olive oil, legumes and certain dairy products) and associations with mood, stress, and anxiety have been examined in multiple studies (Ford, Jaceldo-Siegl, Lee, Youngberg, \& Tonstad, 2013; Hodge, Almeida, English, Giles, \& Flicker, 2013). When Mediterranean foods were compared with typical Western foods (red and processed meats, sweets/desserts, soda and fast food) in over 9,000 older adults, subjects demonstrated a positive association with positive affect (i.e. improved mood, lower stress, better subjective wellness) and Mediterranean foods. This was seen specifically with the intake of fresh produce, olive oil, nuts, and legumes (Ford et al., 2013). Additionally, fresh vegetables, fresh fruits and nuts were inversely associated with negative 
affect. Western foods, including fast food, sweets/desserts and soda were correlated with poor mood state. Red meat intake and frequent consumption of fast food were associated with negative affect only in women (Ford et al., 2013). Similar results were observed in a study of over 8,500 older adults (Hodge et al., 2013). Higher stress levels were more likely when subjects followed an Australian eating pattern (some fresh produce, cheddar cheese, whole-meal bread, margarine, pudding, lamb, cereal), while lower stress scores were associated with a Mediterranean dietary pattern in this observational study. Higher total energy intake was positively associated with stress. Adherence to a typical Australian diet, which is not considered a particularly healthful way of eating, was also associated with lower stress in some subjects at follow-up. The authors speculated that this reduced stress might be due to a connection with community through a traditional dietary pattern (Hodge et al., 2013).

The Mediterranean dietary pattern is just one of many dietary patterns that has been assessed in relation to emotions and stress. Among Iranian adults, consumption of unsaturated oils, fresh produce, grains, meat and dairy were all higher in subjects with lower stress levels (Roohafza et al., 2013). High-stress individuals consumed more saturated oils than did individuals in the lowstress group. Overall Global Dietary Index scores were lower (indicating a better diet), and the overall dietary pattern was better in the low-stress group. A positive correlation was found between stress levels and saturated oil intake while consumption of fresh produce and unsaturated oils showed an inverse association with stress (Roohafza et al., 2013).

An analysis of the Geelong Osteoporosis Study assessed anxiety and depression diagnosis, adverse psychological symptoms (General Health Questionnaire, GHQ-12), and diet (Jacka et al., 2010). Overall diet quality score (based on adherence to Australian guidelines for healthy eating) was inversely related to GHQ-12 scores, with a more healthful dietary pattern resulting in fewer symptoms. Interestingly, red meat (beef and lamb) was a component of a dietary pattern that was associated with fewer psychological symptoms (the Traditional diet of produce, beef, lamb, fish and whole grains) as well as the dietary pattern associated with more psychological symptoms (the Western diet of meat, pies, processed meats, pizza, chips, burgers, white breads, flavored drinks, beer and sugars) (Jacka et al., 2010).

Further examination of the Geelong Osteoporosis Study found that there was no association between magnesium, zinc, or folate and anxiety (Jacka, Maes, Pasco, Williams, \& Berk, 2012a). When examining fish intake, subjects with the highest DHA intake had nearly $50 \%$ less likelihood of suffering from anxiety than those with the lowest intake (Jacka et al., 2013). Smokers demonstrated a stronger association between fish consumption and reduced psychological symptoms compared to non-smokers. The authors suggested this might be due to fish consumption providing more protection in the case of increased oxidative stress (Jacka et al., 2013). Higher red meat intake was not associated with anxiety. Overall, red meat intake below the recommended guidelines for Australians was associated with more psychological symptoms and higher likelihood of an anxiety diagnosis (Jacka et al., 2012b).

Another study examined three different dietary patterns, including Healthy (produce, salads, pasta, rice, cereals, fish, wine and unprocessed meats), Western (meat, liver, processed meats, salty snacks, pizza, sugars and sweets, soft drinks, margarine, mayonnaise/dressings, fries, beer, and coffee), and traditional Norwegian (fish/shellfish, potatoes, produce, butter and margarine, milk and yogurt, pasta, rice, bread, meat/meat spreads, legumes and eggs) patterns (Jacka, Mykletun, Berk, Bjelland, \& Tell, 2011). While women demonstrated a reduced risk of anxiety with an increase in diet quality score, this was not seen in men. Men had an increased risk for anxiety linked with both the Western and Healthy patterns. The most interesting relationship here was that the Healthy eating pattern was positively associated with anxiety in men and 
negatively in women; although the authors offer possible explanations of type I error or reverse causality to explain these results (Jacka et al., 2011). It could also be that men find comfort in the foods that are considered unhealthy, and the psychological effect of consuming these foods improves emotional wellness.

The effect of animal foods on mood has been investigated. A RCT examined effects of meat and fish intake on mood in 39 healthy omnivorous humans. Subjects were split into three dietary intervention groups: OMN (continue eating meat/fish/poultry at least 1x/day), FISH (consume fish 3-4x/week but avoid meat and poultry), and VEG (avoid all animal-based foods except dairy) (Beezhold \& Johnston, 2012). VEG participants had much greater improvement in stress and confusion scores, and moderately better tension/anxiety and Profile of Mood State total scores compared to the other two groups. Increasing fish consumption and avoiding meat did not improve mood or reduce stress (Beezhold \& Johnston, 2012).

Some common patterns between diet and stress and anxiety were demonstrated. Dietary patterns including fresh produce (Ford et al., 2013; Jacka et al., 2010; Jacka et al., 2011; Roohafza et al., 2013), whole grains (Jacka, et al., 2010; Roohafza et al., 2013), and fish (Ford et al., 2013; Jacka et al., 2010; Jacka et al., 2011) were associated with lower psychological distress and anxiety. In contrast, sweets and processed meats (Ford et al., 2013; Jacka et al., 2010; Jacka et al., 2011), pizza, beer and salty snacks/chips (Jacka et al., 2010; Jacka et al., 2011) were included in dietary patterns associated with higher stress and anxiety. Meat intake and association with emotional wellness was unclear. For examples, red meat was included in dietary patterns that were associated with lower (Jacka et al., 2010; Roohafza et al., 2013) and with higher emotional distress (Jacka et al., 2010), and removing meat and fish entirely resulted in reduced stress and improved mood (Beezhold \& Johnston, 2012). Findings for emotional wellness were not consistent between men and women. Women had a higher association between foods considered unhealthy (red meat, fast food, Western dietary patterns) and negative affect than men did (Ford et al., 2013; Hodge et al., 2013). Moreover, adherence to a healthy dietary pattern was associated with decreased anxiety in women and increased anxiety in men. Reverse causation and residual confounding of other lifestyle factors cannot be ruled out in observational studies, even though the majority of the studies did control for such factors. Further research focusing on the difference between men and women, and focusing on red meat consumption, in relation to diet and stress and anxiety is needed.

Overall, the Western style of eating was associated with poorer emotional wellness based on anxiety and stress, while Mediterranean dietary patterns were associated with improved emotional wellness (Ford et al., 2013; Hodge et al., 2013). Older adults may reduce stress and improve emotional wellness by consuming more fruits and vegetables, whole grains, nuts, and fish while avoiding highly processed foods such as sweets, salty snacks, and processed meats. The majority of the research provided here was based on cross-sectional or observational information, and therefore cannot prove causation. Future research regarding emotional wellness and dietary intake should include RCTs with a focus on the impact of both Westernand Mediterranean-style eating and the effect on anxiety and stress.

\subsection{Physical Wellness}

Physical wellness addresses the need for regular physical activity and encourages healthy eating and exercise. Physical wellness follows the general guideline that it is better to eat foods that enhance good health and avoid those that impair it (Hettler, 1976). Foods that enhance good health could mean a variety of things. Since the three previously discussed dimensions of wellness may be improved with the intake of whole foods, the focus for physical wellness will 
be to examine all-cause mortality as it relates to whole foods versus processed foods (see Appendix, Table D for a detailed description of research).

Public health officials have designed dietary guidelines specifically to improve physical wellness. The World Health Organization dietary guidelines to protect against chronic disease can be measured using the Healthy Diet Indicator (HDI). The HDI has been inversely associated with death (Knoops et al., 2006), with a 13\% reduced risk of all-cause death for those scoring highest (healthiest) compared to those scoring lowest (least healthy) (Huijbregts et al., 1997). This inverse relationship between HDI and mortality was even stronger for cardiovascular disease and cancer-related deaths, specifically (Huijbregts et al., 1997). Adherence to U. S. dietary guidelines may also improve survival. Survival rates were $20 \%$ higher for women and $28 \%$ higher for men in the highest quartile of adherence to the recommended healthy eating behaviors compared to those in the lowest quartile (Kant, Graubard, \& Schatzkin, 2004).

Adherence to the Mediterranean dietary pattern has been associated with improved survival rates (Knoops et al., 2006; Osler \& Schroll, 1997). This association may be age-sensitive, however. One study of older and younger women found that a Mediterranean diet score was not associated with all-cause or cancer deaths in women aged 30-39. However, the Mediterranean diet score was associated with reduced total and cancer deaths in women 40 years old or older (Lagiou et al., 2006).

Aside from the Mediterranean dietary pattern, other patterns have been examined. One study compared a Healthy Foods pattern (high in whole foods, low in meat and processed foods) with both a High-Fat Dairy Products and with a Sweets and Desserts pattern (Anderson et al., 2011). The Healthy Foods group was associated with more years of healthy life and had the lowest mortality rates. Similarly, when assessing the benefits of plant-based dietary patterns in older Europeans, the plant-based dietary pattern was associated with reduced mortality rates (Bamia et al., 2007). Similarly, a prudent dietary pattern (frequent intake of whole-meal bread, pasta, rice, oatmeal, fruits, vegetables and fish) was inversely associated with mortality and CVD. In the same study, a Western dietary pattern that was typical of a Danish dietary pattern (frequent intake of sausages, meat, potatoes, butter and white bread) was not associated with mortality (Osler, Heitmann, Gerdes, Jorgensen, \& Schroll, 2001). A similar Western dietary pattern (high in refined grains, red and processed meats, high-fat dairy, desserts and French fries) was compared with a prudent dietary pattern (high in fruits, vegetables, whole grains, legumes, poultry and fish) in over 69,000 women. The prudent pattern was significantly and inversely related to coronary heart disease (CHD) risk and the Western pattern was associated with a higher risk of myocardial infarction. Women eating more whole foods demonstrated lower risk of CHD than those eating more processed foods (Fung, Willett, Stampfer, Manson, \& Hu, 2001).

Low-fat, high-carbohydrate diets have also been examined. Traditionally healthy diets $(>55 \%$ carbohydrates, $<30 \%$ fat, and approximately $15 \%$ protein) have recently been questioned in favor of diets that have lower carbohydrate $(<40 \%)$ combined with higher fat $(>40 \%)$ and higher protein $(>20 \%)$ intake. In one study, low carbohydrate therapy was more effective than the traditional diet in treating diabetes. Diabetics who adopted a low carbohydrate diet ( $<130$ grams per day) reduced their blood glucose levels, reduced body weight, and reduced the need for diabetic medications (Feinman et al., 2014). Matarese and Pories (2014) evaluated a variety of weight loss diets and found evidence that a lower carbohydrate-higher protein diet produced increased metabolic activity, which contributed to increased weight loss compared to traditional diets. A panel of experts reviewed 17 trials on the effectiveness of various low carbohydrate and high fat or protein diets (Jensen et al., 2014). Low fat, moderate carbohydrate diets were also evaluated. In summary, lower carbohydrate diets might produce faster weight loss and reduction of 
diabetes, but the selection of the appropriate diet depends on several factors, such as sensitivity to insulin, body weight, and exercise patterns (Jensen et al., 2014).

Whole grain consumption has been associated with increased survival (Jacobs, Meyer, Kushi, \& Folsom, 1999; Steffen et al., 2003) and lower disease rates (Ruel et al., 2013) in large, observational studies. One serving per day of whole grains could significantly reduce risk of mortality (Jacobs et al., 1999; Steffen et al., 2003) and also reduce risk of hypertension (Wang et al., 2007). Men may be more sensitive to this potential protective effect. One study demonstrated reduced mortality in men, but not women, from following a healthful dietary pattern including high whole-grain intake (Kant et al., 2004).

Older women consume more refined grains than whole grains (Jacobs et al., 1999), which may result in detrimental effects. In one study, refined grains were not associated with all-cause mortality in fully adjusted models, but they were linked to increased coronary artery disease (CAD) risk in African American subjects (Steffen et al., 2003). Refined grains demonstrated a small positive relationship with mortality in another study. However, when women consumed large amounts of both refined and whole grains, the risk associated with refined grains lost significance (Jacobs et al., 1999).

Cereal intake has been assessed with regard to grain consumption and mortality (Knoops et al., 2006; Osler \& Schroll, 1997), with conflicting results. One study of older adults found that every $20 \mathrm{~g}$ increase in cereal intake was associated with a $10 \%$ increased risk of death. When categorized into wheat, rice, or other grains, the other grains cereal category was the only one positively associated with death (Osler \& Schroll, 1997). In contrast, cereal and fiber intake were associated with survival in a much larger study (Knoops et al., 2006). Additionally, Japanese adults consuming fewer whole grains (not including wheat or rice) had higher disease rates (Ruel et al., 2013). On the whole, consumption of whole grains has been associated with increased survival and lower disease rates. Whole grains, however, are not the only food group that could provide protection against mortality.

Fruit and vegetable intake was inversely associated with mortality in a number of studies (Agudo et al., 2007; Kant et al., 2004; Knoops et al., 2006; Ruel et al., 2013). In one study, subjects in the highest quintile of fruit and vegetable intake had a $22 \%$ reduced total mortality risk compared to those in the lowest quintile (Steffen et al., 2003). Similarly, among over 126,000 older adults examined, there was a $20 \%$ lower risk of CHD for those in the highest quintile of fruit and vegetable intake than those in the lowest (Joshipura et al., 2001). The 5-A-Day public health campaign promoting fruit and vegetable intake has also been examined (Genkinger, Platz, Hoffman, Comstock, \& Helzlsouer, 2004). Subjects who adhered to the guidelines had lower rates of all-cause and cancer deaths.

This positive association between fruits and vegetables and survival could be due to antioxidant status. One study found that subjects in the highest quartile for plant-based foods had nearly four times the antioxidant and total-antioxidant-capacity levels of those in the lowest quartile (Agudo et al., 2007). Increased lycopene intake resulted in a clear, linear relationship with reduced mortality rates (Agudo et al., 2007). Other antioxidants such as vitamin C, pro-vitamin A carotenoids (Agudo et al., 2007), and beta-carotene (Genkinger et al., 2004) were associated with greater survival rates, but to a lesser extent. Associations with vitamin $C$ consumption and mortality were conflicting, however (Agudo et al., 2007; Genkinger et al., 2004).

Finally, while associations with fruits, vegetables and antioxidants may be fairly consistent, results for fat and mortality are inconclusive. Dietary fat has been associated with higher risk of developing multi-morbidity in healthy subjects (Ruel et al., 2013), although subtypes of fat (i.e.: saturated, trans) were not differentiated. Saturated fat intake has been both positively associated 
with mortality (Knoops et al., 2006) and negatively associated with comorbidity (Ruel et al., 2013). Thus, further research regarding fats and all-cause mortality is needed. However, it should be noted that foods high in saturated fats (i.e.: high-fat dairy products, meat) were included in dietary patterns linked to increased mortality (Anderson et al., 2011) and myocardial infarction (Fung et al., 2001). These items were typically not included in dietary patterns that were associated with increased survival (Anderson et al., 2011; Bamia et al., 2007; Huijbregts et al., 1997; Kant et al., 2004).

There are a number of factors to consider when examining the research regarding whole foods and mortality. Paradoxically, in one study, elevated serum cholesterol was associated with a significant reduction in risk of death (Osler \& Schroll, 1997). This is contrary to other studies of this nature and might be due to the age of the subjects. Those with high serum cholesterol may be more likely to die at middle age, therefore leading to a weaker correlation between serum cholesterol and mortality in older adults (Staessen et al., 1990).

Associations between refined grains and mortality were also inconclusive. Adjustment for whole grains attenuated the risk of mortality from refined grains. This suggests that consuming whole grains might "cancel out" the consumption of refined grains to some extent. Given that the association between refined grain consumption and mortality was small, this could simply mean that the protective effect of whole grains is stronger than the detrimental effect of refined grains. In addition, refined grains were associated with CAD but not ischemic stroke (Steffen $e t$ al., 2003). This could suggest that refined grains are not associated with clots in general, but rather to clots in specific anatomical areas such as the heart but not the brain. These results could also simply be due to residual confounding, meaning other non-dietary factors are involved. Additional research is needed in these areas. In regard to conflicting evidence for grain intake, it may benefit future researchers to differentiate between whole-grain cereals and refined-grain cereals. Breaking down grains into whole or refined, in addition to the grain type (i.e.: oats, rice, wheat), could provide clarification.

Interestingly, one study demonstrated that men with the lowest adherence to healthy eating had the lowest mortality risk (Osler et al., 2001). This could be the result of residual confounding, or the results could have been erroneous, as they were not in line with the other research. Finally, due to the fact that it would be unethical to complete an intervention to assess dietary pattern and death rates, all research for mortality is based on observation. This research cannot rule out residual confounding and/or reverse causation. Future research should continue to focus on serum cholesterol levels, whole grain consumption, and Western dietary patterns, and the associations of each with health and longevity.

While the research provided here is not definitive due to research design and lack of controlled clinical trials, some patterns associating physical wellness and diet were observed. Adherence to dietary public health guidelines could protect against premature death. Following a Mediterranean style dietary pattern might reduce risk of all-cause and cause-specific mortality, while a Western dietary pattern might increase risk of myocardial infarction and death. The components of a Western dietary pattern are typically more processed (i.e.: processed meats, sweets, refined grains) than those in the Mediterranean dietary pattern. Whole foods including fruits, vegetables, fish, and whole grains are standard Mediterranean fare and were inversely associated with mortality. Simply put, older adults may increase their survival rates, therefore improving physical wellness, by consuming more whole foods such as produce and whole grains while avoiding processed foods. 


\subsection{Spiritual Wellness}

Spiritual wellness is related to a person's search for the meaning and purpose of human existence. One achieves spiritual wellness when actions become consistent with beliefs and values (Hettler, 1976). Considering spiritual wellness as it relates to nutrition, many faith-based dietary interventions have attempted to instill healthier eating habits. Examined here are the effects of spiritual wellness, focusing on faith-based healthy lifestyle interventions on dietary intake (see Appendix, Table E for a detailed description of research).

Relationships between spirituality and dietary pattern have been observed. Among National Health and Nutrition Examination Survey (NHANES) III subjects, African American women and older Mexican American men who frequently attended church services had higher fish intake (Obisesan, Livingston, Trulear, \& Gillum, 2006). However, there was no significant relationship between attendance at religious services and dietary macronutrient intake (Obisesan et al., 2006). While this observation does not clearly draw conclusions or determine causation between spiritual wellness and nutrition, some correlations between the two may be evident. In one 15month faith-based RCT, physical activity and fruit and vegetable consumption were higher in the intervention group compared to control subjects (Wilcox et al., 2013). Dietary behavior changes included decreased fat-related behaviors (43\%), improved fiber-related behaviors (42\%), and increased fruit and vegetable intake (33\%) (Baruth \& Wilcox, 2013). Written information (i.e. handouts) was positively associated with improved dietary pattern while spoken support (i.e. messages from the pulpit) resulted in higher produce intake (Baruth, Wilcox \& Condrasky, 2011).

Another faith-based intervention study examined a church-wide approach to dietary changes, including optional individual counseling (Resnicow et al., 2004). Overall, this Body and Soul intervention was successful at increasing intake of fruits and vegetables and improving post-test fat intake, among other variables (Resnicow et al., 2004). Increased produce consumption and decreased fat intake were associated with receiving the educational materials and attending the kick-off event, while attendance at other events (i.e. classes) was also related to higher fruit and vegetable intake (Campbell, Resnicow, Carr, Wang, \& Williams, 2007). Receiving motivational interview (MI) had a positive effect on diet and motivation only if the interviewer had strong listening skills and/or made calls frequently (Campbell et al., 2007).

A 6-month quasi-experimental follow-up focused on healthier eating and increased activity (Thomson, Zoellner, \& Tussing-Humphreys, 2014). The intervention included health-related scripture messages delivered from the pulpit, monthly newsletters, and a church-wide effort to include healthy foods and drinks at functions. Control subjects received health information via bi-monthly newsletters. Attendance was directly associated with success. High-attendance intervention subjects demonstrated improved dietary quality on all six components of the Healthy Eating Index (HEI-2005) while low-attendance subjects demonstrated no significant change. Interestingly, control subjects showed increases in fruit and in total scores. Overall, social support seemed to be a good predictor of a dietary pattern change (Thomson et al., 2014). In contrast, dietary habits were not positively impacted in an 8-week faith-based intervention, although intervention subjects did reduce body weight (Bopp et al., 2009). Another 8-week intervention resulted in reduced body fat and weight, but it was not apparent whether these changes were a result of dietary changes or physical activity, as both were included in the intervention (Woods et al., 2013). Similarly, an 8-week intervention focusing on diet and activity to reduce metabolic risk factors resulted in an average $6 \%$ reduction of body weight and a lower average number of metabolic risk factors (Ivester et al., 2010). However, it was unclear whether these results were from physical activity, dietary changes, or both. 
While the studies presented here included actual interventions and not simply observation, they often included multiple intervention strategies (i.e. physical activity as well as dietary pattern). As a result, positive effects of interventions may be due to multiple strategies. Samplings may not be representative of the entire population. In addition, the spiritual component of each program varied, with some including multiple spiritual components such as health-related scripture readings (Bopp et al., 2009; Thomson et al., 2014), healthy messages from church leadership (Resnicow et al., 2004; Thomson et al., 2014), congregation-wide changes (Resnicow et al., 2004; Thomson et al., 2014; Wilcox et al., 2013) and prayer (Ivester et al., 2010), while others strictly used the church as a meeting area (Woods et al., 2013). Spirituality also cannot be assumed based on church attendance alone. However, as the NHANES III analysis previously mentioned, spirituality is often assessed based on church attendance due to lack of other measures (Obisesan et al., 2006).

Based on the evidence from multiple RCTs, faith-based interventions can improve dietary patterns and overall health. Interventions focused on structural and organizational changes (Campbell et al., 2007; Wilcox et al., 2013) can help participants to change one or more dietary behaviors. Success rates may be higher for programs of longer duration, and for those including a specific dietary focus (Bopp et al., 2009; Resnicow et al., 2004; Wilcox et al., 2013; Woods et al., 2013).

Older adults should seek a spiritual organization that is in line with their own beliefs and values and that supports healthy dietary behaviors. This includes organizations that provide healthy living classes (Resnicow et al., 2004), handouts regarding healthy lifestyles (Baruth et al., 2011; Resnicow et al., 2004), and/or organization leaders/pastors who lead by example (Baruth et al., 2011) in regard to healthy living. Overall, spiritual wellness by way of faith-based dietary interventions can positively impact nutrition if the individual is actively engaged and integrated into the community and the program.

\subsection{Social Wellness}

Social wellness focuses on one's community and environment, seeking to improve one's world by promoting healthy lifestyles and also communication in one's life. Social wellness includes enhancing personal relationships and building a stronger community (Hettler, 1976). Examined here are the effects of social interactions and communication with others, both at and outside of meals, on dietary intake in older adults (see Appendix, Table F for a detailed description of research).

In 2010, 19\% of men aged 65 years or older and nearly twice as many women of the same age lived alone (Federal Interagency Forum on Aging-Related Statistics 2012, 2014). In the NHANES III observational study of subjects aged 65+ years examining eating and social life, living arrangements did not seem to be associated with dietary intake (Sahyoun \& Zhang, 2005). However, in an observational study of over 9,500 adults, lone-living men and women had lower fruit and vegetable intake, with men's scores lower than women's, compared to cohabitating people (Conklin et al., 2013). In 2010, fewer than half of those aged 65-74 years old were married, and that proportion declined among the older population (Federal Interagency Forum on AgingRelated Statistics 2012, 2014). Observational study results demonstrated lower vegetable scores for both widowed men and women, compared to partnered people. Widowed men's vegetable scores were almost half those of widowed women's, and men's' dietary patterns overall were more negatively affected than those of women in regard to living alone, being un-partnered and having limited contact with friends (Conklin et al., 2013). Place of residence may also be associated with marital status and dining companions. In one study of 58 older adults, subjects 
living in senior communities were more likely to be single and to dine with friends. Conversely, those living in private housing were more likely to be married and, therefore, to dine with a spouse (Cohen-Mansfield \& Jensen, 2009).

In one study, over half of older adults reported feeling lonely (Payette, Gray-Donald, Cyr, \& Boutier, 1995). A greater degree of contact with friends in un-partnered/unmarried people was associated with higher fruit and vegetable scores compared to un-partnered/unmarried people with infrequent contact with friends (Conklin et al., 2013). Similarly, those reporting having friends had higher energy intake than those who did not have friends (Payette et al., 1995). In an analysis of NHANES III results, limited social contact was significantly associated with lower HEI scores, lower intake of vitamin C, and fewer calories consumed. Authors suggest that limited social contact may be an independent risk factor for poorer dietary pattern quality (Sahyoun \& Zhang, 2005). In contrast, weekly family contact (instead of daily) was more positively associated with vegetable variety in women from the European Prospective Investigation of Cancer (EPIC) study (Conklin et al., 2013). Perhaps this is a result of older women feeling that they are monitored by family members when they are checked on daily, versus feeling a more social nature in onceper-week interactions.

In addition to living arrangements and overall social contact, dining companions may also impact dietary choices. Adults $65+$ years old report less communal dining than do younger adults (de Castro, 2002). Even so, total intake of food was greater when dining with a companion for all ages than when dining alone (de Castro, 2002), indicating that social facilitation of caloric intake is not attenuated with age. In an observational study of 515 slightly younger adults (average age of 41.9 years), meals eaten with a spouse, family, or friends were significantly larger than meals eaten with other companions (de Castro, 1994). When dining with a spouse or with family, meals were large and eaten more quickly, while dining with friends resulted in large meals eaten more slowly. Meals eaten alone were always small and of short duration. There was also a significant positive correlation between the total number of companions present at a meal and the amount of calories consumed (i.e. the more people present at the meal, the more calories consumed). Similar results were seen in 50 older adults, mean age 77 years, where average intake of calories at meals eaten with a companion was 114 calories higher than at meals eaten alone (Locher, Robinson, Roth, Ritchie, \& Burgio, 2005).

It must be noted that two of the studies mentioned (de Castro, 1994; de Castro, 2002) included subjects with a mean age lower than the target population of this paper. Also, many studies included (Conklin et al., 2013; de Castro, 1994; Sahyoun \& Zhang, 2005) were observational and, therefore, cannot define causation. In addition, samplings of convenience were used (CohenMansfield \& Jensen, 2009).

On the whole, increased social contact can improve dietary intake. Therefore, individuals living alone might benefit from actively and intentionally seeking out social contacts. While reported participation in clubs and senior centers has been low (Payette et al., 1995), participation in such activities might be a good way to engage with others. Even phone contact on its own demonstrated a positive impact on fruit and vegetable intake (Sahyoun \& Zhang, 2005), so if mobility is an issue, calling friends or family regularly may improve the dietary pattern. In addition to increasing social contact, communal dining may increase caloric intake and so older adults are encouraged to seek dining companions when possible.

\section{Discussion}

Overall, it is clear that one's dietary pattern can impact wellness, and vice versa. There is an abundance of overlap between the six dimensions, as demonstrated in Table 1 below. For 
example, intellectual wellness (memory retention) can be applied to occupational wellness. Antioxidants (specifically lycopene) were associated with improved intellectual and physical wellness. While PUFA intake may be low in older adults (Jacka et al., 2013; Payette et al., 1995), omega-3 PUFAs were associated with both improved intellectual and emotional wellness. Spiritual wellness positively impacted not only nutrition, but also emotional wellness by reducing stress (Ivester et al., 2010). Additionally, improved social wellness is associated with improvements in diet.

Table 1. The interrelationships between dietary intake patterns and the six dimensions of wellness

\begin{tabular}{|c|c|c|c|}
\hline Wellness dimension & Positive relationship & $\begin{array}{l}\text { Negative } \\
\text { relationship }\end{array}$ & $\begin{array}{l}\text { Inconclusive } \\
\text { evidence }\end{array}$ \\
\hline Intellectual & $\begin{array}{l}\text { PUFA } \\
\text { Fruits \& vegetables } \\
\text { Antioxidants } \\
\text { Mediterranean diet } \\
\text { Fish oils } \\
\text { Occupational wellness }\end{array}$ & $\begin{array}{l}\text { Saturated fats } \\
\text { Sweets }\end{array}$ & \\
\hline Occupational & PUFA & $\begin{array}{l}\text { Saturated fats } \\
\text { Missed meals }\end{array}$ & \\
\hline Emotional & $\begin{array}{l}\text { Mediterranean diet } \\
\text { Whole grains } \\
\text { Fish oils }\end{array}$ & $\begin{array}{l}\text { Sweets } \\
\text { Western diet }\end{array}$ & Saturated fats \\
\hline Physical & $\begin{array}{l}\text { Fruits \& vegetables } \\
\text { Antioxidants } \\
\text { Mediterranean diet } \\
\text { Whole grains } \\
\text { Fish oils }\end{array}$ & Western diet & \\
\hline Spiritual & $\begin{array}{l}\text { Fruit and vegetable } \\
\text { intake } \\
\text { Emotional wellness } \\
\text { Social wellness }\end{array}$ & & \\
\hline Social & $\begin{array}{l}\text { Total energy intake } \\
\text { Fruit and vegetable } \\
\text { intake }\end{array}$ & & \\
\hline
\end{tabular}

To maximize wellness through nutrition, older adults should consider increasing their intake of whole foods such as fruits, vegetables, whole grains, and fish. These foods were associated with improved intellectual, emotional, and physical wellness. Occupational wellness may be improved based more on the timing of meals rather than their content, consuming balanced meals containing PUFA, and avoiding missing meals at work. While following a primarily whole-foods dietary pattern can improve wellness, quality of life must also be considered. Therefore, treats and/or culturally traditional foods that may not be considered healthful should 
be consumed in moderation. Table 2 below summarizes the results of each wellness dimension as it relates to diet.

Table 2. Wellness and dietary intake summary

\begin{tabular}{ll}
\hline Wellness Dimension & Steps to Improve Wellness and/or Diet \\
\hline Intellectual & Increase consumption of antioxidant-rich, whole foods such as \\
coffee, alcohol (moderate intake), walnuts, fruits, vegetables, and \\
fatty fish \\
Decrease consumption of processed foods such as sweets, \\
processed animal products, dietary cholesterol, and cereals \\
Increase consumption of thiamin, folate, and vitamin C \\
Adopt a Mediterranean dietary pattern \\
Avoid high-fat meals and large portions between 11:00am-3:00pm \\
Consume meals with moderate amounts of fat, primarily PUFA, \\
during work hours \\
Avoid missing meals during work hours \\
Increase consumption of fruits, vegetables, whole grains, nuts and \\
fish \\
Decrease consumption of saturated oils and processed foods such \\
as sweets, salty snacks, and processed meats \\
Avoid a Western dietary pattern \\
Adopt a Mediterranean dietary pattern \\
Increase consumption of whole grains, fish, fruits and vegetables \\
Decrease consumption of processed meats, sugars and refined \\
carbohydrates \\
Avoid a Western dietary pattern \\
Adopt a Mediterranean dietary pattern \\
Seek an organization that is in line with a person's own beliefs \\
and values \\
Engage in faith-based healthful dietary interventions, including \\
healthy living classes and handouts, and leadership who live \\
healthfully \\
Dine with companions when possible \\
Seek social contacts through community and/or over the phone \\
\hline Physical
\end{tabular}

Meat intake was positively associated with a number of outcomes, including impaired intellectual and physical wellness when consumed as part of a traditional Western dietary pattern (Fung et al., 2001). However, when meat intake was below recommended amounts, increased psychological symptoms were present (Jacka et al., 2012). This may indicate a U-shaped relationship, where intakes of meat above or below recommendations could result in impaired wellness. Thus, older adults should adhere to the recommended intakes of red meat, focusing on lean cuts and removing fat when able in order to keep saturated fat intakes low. Adherence to the 5-A-Day fruit and vegetable guidelines might also improve intellectual and physical wellness. 
In regard to the impact of spiritual and social wellness on nutrition, older adults would benefit from being actively engaged in a spiritual organization that practices a multi-faceted approach to healthy living. This should include healthy messages from the leadership, information through written materials, and support and information through group activities. Social wellness, including more social contacts either in person or over the phone, can improve dietary intake in older adults. Dining with companions might also improve dietary intake. Older adults with lower than desired energy intake should consider eating with others when possible in order to increase caloric intake.

Future research should be directed toward wellness in its entirety, rather than each component separately. Randomized controlled trials with dietary interventions including increased antioxidants and whole foods and limited processed foods should focus on subjective feelings of wellness and objective measures for all six dimensions. Research should be done across all ages to assess how dietary patterns throughout life may impact wellness. In addition, further analysis of data from national cohort studies such as NHANES could focus on each of the six dimensions as they pertain to nutrition, to identify common trends.

Limitations of this review include the use of food frequency questionnaires (FFQ) as a primary assessment for dietary intake in many of the studies. Establishing dietary intake through FFQ may be subject to misreporting. Also, a large number of studies referenced were observational in nature and, therefore, cannot prove causation. Among the RCTs included, many were focused on specific populations (i.e.: ethnicity, disease risk, etc.) and results, therefore, may not be generalized to the entire older-adult population. Additionally, wellness includes many other factors than are detailed here. For example, physical wellness could focus on mobility rather than mortality. Because of the vast amount of information available and the subjective interpretation of wellness, results here were narrowed to focus on only one component for each of the six dimensions. In addition, the tools used to interpret wellness in this paper were not designed specifically with wellness in mind. For example, the GHQ-12 assessment was designed to assess various psychological symptoms and not emotional wellness in its entirety. However, given the available research, the GHQ-12 assessment was used in this paper to interpret stress and anxiety, and those findings were then applied to overall emotional wellness. It should also be noted that intake of healthy foods is often associated with other healthy behaviors (Jacobs et al., 1999; Kant et al., 2004; Lagiou et al., 2006; Steffen et al., 2003), and therefore reverse causation or residual confounding cannot be ruled out.

Intellectual, occupational, emotional, physical, spiritual and social wellness are all integrated. Personal wellness is achieved by living intentionally through all aspects of life; and by achieving personal wellness a person will feel more complete and happy. To put the matter simply, older adults can improve wellness by increasing the intake of plant-based foods and avoiding highly processed foods. Older adults can also improve dietary intake by enriching wellness, seeking out and engaging in a spiritual community that encourages healthy lifestyles and seeking dining companions and social interaction.

\section{Authors}

Angela G. Dalton

Central Michigan University

John V. Logomarsino

Central Michigan University

Jack.logomarsino@cmich.edu 


\section{Publishing Timeline}

Received 27 April 2014

Accepted 27 November 2014

Published 31 December 2014

\section{References}

Agudo, A., Cabrera, L., Amiano, P., Ardanaz, E., Barricarte, A., Berenguer, T., . . \& Gonzalez, C. A. (2007). Fruit and vegetable intakes, dietary antioxidant nutrients, and total mortality in Spanish adults: findings from the Spanish cohort of the European Prospective Investigation into Cancer and Nutrition (EPIC-Spain). American Journal of Clinical Nutrition, 85(6), 1634-1642.

American Psychological Association (2014). Anxiety. http://www.apa.org/topics/anxiety/index.aspx

Anderson, A. L., Harris, T. B., Tylavsky, F. A., Perry, S. E., Houston, D. K., Hue, T. F., . . \& Sahyoun, N. R. (2011). Dietary patterns and survival of older adults. Journal of the American Dietetic Association, 111(1), 84-91. http://dx.doi.org/10.1016/j.jada.2010.10.012

Bamia, C., Trichopoulos, D., Ferrari, P., Overvad, K., Bjerregaard, L., Tjonneland, A., . . \& \& Trichopoulou, A. (2007). Dietary patterns and survival of older Europeans: the EPIC-Elderly study (European Prospective Investigation into Cancer and Nutrition). Public Health Nutrition, 10(6), 590-598. http://dx.doi.org/10.1017/S1368980007382487

Baruth, M., \& Wilcox, S., (2013). Multiple behavior change among church members taking part in the Faith, Activity, and Nutrition program. Journal of Nutrition Education and Behavior, 45(5), 428-434. http://dx.doi.org/10.1016/j.jneb.2013.03.002

Baruth, M., Wilcox, S., \& Condrasky, M. D. (2011). Perceived environmental church support is associated with dietary practices among African American adults. Journal of the American Dietetic Association, 111(6), 889-893. http://dx.doi.org/10.1016/j.jada.2011.03.014

Beezhold, B. L., \& Johnston, C. S. (2012). Restriction of meat, fish and poultry in omnivores improves mood: a pilot randomized controlled trial. Nutrition Journal, 11(9). http://dx.doi.org/10.1186/1475$\underline{2891-11-9}$

Berr, C., Portet, F., Carriere, I., Akbaraly, T. N., Feart, C., Gourlet, V., . . Ritchie, K. (2009). Olive oil and cognition: results from the Three-city study. Dementia and Geriatric Cognitive Disorders, 28(4), 357-364. http://dx.doi.org/10.1159/000253483

Bookheimer, S. Y., Renner, B. A., Ekstrom, A., Li, Z., Henning, S. M., Brown, J. A., . . \& Small, G. W. (2013). Pomegranate juice augments memory and fMRI activity in middle-aged and older adults with mild memory complaints. Evidence Based Complementary and Alternative Medicine, 2013. http://dx.doi.org/10.1155/2013/946298

Bopp, M., Wilcox, S., Laken, M., Hooker, S. P., Parra-Medina, D., Saunders, R., . . McClorin, L. (2009). 8 steps to fitness: a faith-based, behavior change physical activity intervention for African Americans. Journal of Physical Activity and Health, 6(5), 568-577.

Campbell, M. K., Resnicow, K., Carr, C., Wang, T., \& Williams, A. (2007). Process evaluation of an effective church-based diet intervention: Body \& Soul. Health Education and Behavior, 34(6), 864-880. http://dx.doi.org/10.1177/1090198106292020

Carstensen, L. L., Turan, B., Scheibe, S., Ram, N., Ersner-Hershfield, H., \& Samanez-Larkin, G. R. (2011). Emotional experience improves with age: Evidence based on over 10 years of experience sampling. Psychology and Aging, 28(1), 21-33. http://dx.doi.org/10.1037/a0021285

Cohen-Mansfield, J., \& Jensen, B. (2009). A comparison of eating practices of independently living older adults in private residences and in senior retirement housing: A pilot study. Journal of Nutrition for the Elderly, 28(4), 394-407. http://dx.doi.org/10.1080/01639360903393531

Conklin, A. I., Forouhi, N. G., Surtees, P., Khaw, K. T., Wareham, N. J., \& Monsivais, P. (2013). Social relationships and healthful dietary behavior: Evidence from over-50's in the EPIC cohort, UK. Social Science and Medicine, 100, 167-175. http://dx.doi.org/10.1016/j.socscimed.2013.08.018

de Castro, J. M. (1994). Family and friends produce greater social facilitation of food intake than other companions. Physiology \& Behavior, 56(3), 445-455. http://dx.doi.org/10.1016/0031-9384(94)90286-0 
de Castro, J. M. (2002). Age-related changes in the social, psychological, and temporal influences on food intake in free-living, healthy, adult humans. Journal of Gerontology, 57(6), M368-M377. http://dx.doi.org/10.1093/gerona/57.6.M368

Federal Interagency Forum on Aging-Related Statistics. (2006). Older Americans Update 2006: Key indicators of well-being. http://www.agingstats.gov/agingstatsdotnet/Main Site/Data/2006 Documents/OA 2006.pdf

Federal Interagency Forum on Aging-Related Statistics. (2012). Older Americans 2012: Key indicators of well-being.

http://www.agingstats.gov/agingstatsdotnet/Main Site/Data/2012 Documents/Docs/EntireChartboo k.pdf

Feinman, R. D., Pogozelski, W. K, Astrup, A., Bernstein, R. K., Fine, E. J., Westman, E. C., . . \& Worm, N. (2014). Dietary carbohydrate restriction as the first approach in diabetes management. Nutrition, in press. http://dx.doi.org/10.1016/j.nut.2014.06.011

Folstein, M.E., Folstein, S.E., \& McHugh, P.R. (1975). "Mini-mental state". A practical method for grading the cognitive state of patients for the clinician. Journal of Psychiatric Research, 12, 189-198. http://dx.doi.org/10.1016/0022-3956(75)90026-6

Ford, P. A., Jaceldo-Siegl, K., Lee, J. W., Youngberg, W., \& Tonstad, S. (2013). Intake of Mediterranean foods associated with positive affect and low negative affect. Journal of Psychosomatic Research, 74(2), 142-148. http://dx.doi.org/10.1016/j.jpsychores.2012.11.002

Fung, T. T., Willett, W. C., Stampfer, M. J., Manson, J. E., \& Hu, F. B. (2001). Dietary patterns and the risk of coronary heart disease in women. Archives of Internal Medicine, 161(15), 1857-1862. http://dx.doi.org/10.1001/archinte.161.15.1857

Genkinger, J. M., Platz, E. A., Hoffman, S. C., Comstock, G. W., \& Helzlsouer, K. J. (2004). Fruit, vegetable, and antioxidant intake and all-cause, cancer, and cardiovascular disease mortality in a community-dwelling population in Washington County, Maryland. American Journal of Epidemiology, 160(12), 1223-1233. http://dx.doi.org/10.1093/aje/kwh339

Grandner, M. A., Kripke, D. F., Naidoo, N., \& Langer, R. D. (2010). Relationships among dietary nutrients and subjective sleep, objective sleep, and napping in women. Sleep Medicine, 11(2), 180-184. http://dx.doi.org/10.1016/j.sleep.2009.07.014

Hettler, B. (1976). The six dimensions of wellness. http://www.nationalwellness.org/?page=Six Dimensions

Hodge, A., Almeida, O. P., English, D. R., Giles, G. G., \& Flicker, L. (2013). Patterns of dietary intake and psychological distress in older Australians: benefits not just from a Mediterranean diet. International Psychogeriatrics, 25(3), 456-466. http://dx.doi.org/10.1017/S1041610212001986

Huijbregts, P., Freskens, E., Rasanen, L., Fidanza, F., Nissinen, A., Menotti, A., \& Kromhout, D. (1997). Dietary pattern and 20 year mortality in elderly men in Finland, Italy, and the Netherlands: Longitudinal cohort study. British Medical Journal, 315(7099), 13-17. http://dx.doi.org/10.1136/bmj.315.7099.13

International Journal of Wellbeing (n.d.). Why wellbeing? http://www.internationaljournalofwellbeing.org/index.php/ijow/about/editorialPolicies\#custom-0

Ivester, P., Sergeant, S., C, Danhauer, S., Case, L. D., Lamb, A., Chilton, B. G., . . \& \& Weaver, K. L. (2010). Effect of a multifaceted, church-based wellness program on metabolic syndrome in 41 overweight or obese congregants. Preventing Chronic Disease, 7(4), A81.

Jacka, F. N., Maes, M., Pasco, J. A., Williams, L. J., \& Berk, M. (2012a). Nutrient intakes and the common mental disorders in women. Journal of Affect Disorders, 141(1), 79-85. http://dx.doi.org/10.1016/i.jad.2012.02.018

Jacka, F. N., Mykletun, A., Berk, M., Bjelland, I., \& Tell, G. S. (2011). The association between habitual diet quality and the common mental disorders in community-dwelling adults: the Hordland health study. Psychosomatic Medicine, 73(6), 483-490. http://dx.doi.org/10.1097/PSY.0b013e318222831a

Jacka, F. N., Pasco, J. A., Mykletun, A., Williams, L. J., Hodge, A. M., O'Reilly, S. L., \& Nicholson, G. C. (2010). Association of Western and Traditional diets with depression and anxiety in women. The American Journal of Psychiatry, 167(3), 305-311. http://dx.doi.org/10.1176/appi.ajp.2009.09060881 
Jacka, F. N., Pasco, J. A., Williams, L. J., Mann, N., Hodge, A., Brazionis, L., \& Berk, M. (2012b). Red meat consumption and mood and anxiety disorders. Psychotherapy and Psychosomatics, 81(3), 196-198. http://dx.doi.org/10.1159/000334910

Jacka, F. N., Pasco, J. A., Williams, L. J., Meyer, B. J., Digger, R., \& Berk, M. (2013). Dietary intake of fish and PUFA, and clinical depressive and anxiety disorders in women. The British Journal of Nutrition, 109(11), 2059-2066. http://dx.doi.org/10.1017/S0007114512004102

Jacobs, D. R., Meyer, K. A., Kushi, L. H., \& Folsom, A. R. (1999). Is whole grain intake associated with reduced total and cause-specific death rates in older women? The Iowa Women's Health Study. American Journal of Public Health, 89(3), 322-329. http://dx.doi.org/10.2105/AJPH.89.3.322

Jensen M. D., Ryan, D. H., Apovian, C. M., Ard, J. D., Comuzzie, A. G., Donato, K. A., . . \& Yanovski, S. Z. (2014). 2013 AHA/ACC/TOS guideline for the management of overweight and obesity in adults. Journal of the American College of Cardiology, 63(25), 2985-3023. http://dx.doi.org/10.1016/j.jacc.2013.11.004

Joshipura, K. J., Hu, F. B., Manson, J. E., Stampfer, M. J., Rimm, E. B., Speizer, F. E., . . Willett, W. C. (2001). The effect of fruit and vegetable intake on risk for coronary heart disease. Annals of Internal Medicine, 134(12), 1106-1114. http://dx.doi.org/10.7326/0003-4819-134-12-200106190-00010

Kalmijn, S., van Boxtel, M., Ocke, M., Verschuren, W., Kromhout, D., \& Launer, L. (2004). Dietary intake of fatty acids and fish in relation to cognitive performance at middle age. Neurology, 66(2), 275-280. http://dx.doi.org/10.1212/01.WNL.0000103860.75218.A5

Kant, A. K., Graubard, B. I., \& Schatzkin, A. (2004). Dietary patterns predict mortality in a national cohort: The National Health Interview Surveys, 1987 and 1992. The Journal of Nutrition, 134(7), 17931799.

Knoops, K., de Groot, L., Fidanza, F., Alberti-Fidanza, A., Kromhout, D., \& van Staveren, W. (2006). Comparison of three different dietary scores in relation to 10-year mortality in elderly European subjects: The HALE project. European Journal of Clinical Nutrition, 60(6), 746-755. http://dx.doi.org/10.1038/sj.ejcn.1602378

Krikorian, R., Nash, T. A., Shidler, M. D., Shukitt-Hale, B., \& Joseph, J. A. (2010). Concord grape juice supplementation improves memory function in older adults with mild cognitive impairment. The British Journal of Nutrition, 103(5), 730-734. http://dx.doi.org/10.1017/S0007114509992364

Lagiou, P., Trichopoulos, D., Sandin, S., Lagiou, A., Mucci, L., Wolk, A., . . \& Adami, H.-O. (2006). Mediterranean dietary pattern and mortality among young women: a cohort study in Sweden. The British Journal of Nutrition, 96(2), 384-392. http://dx.doi.org/10.1079/BJN20061824

Landstrom, U., Knutsson, A., \& Lennernas, M. (2000). Field studies on the effects of food content on wakefulness. Nutrition and Health, 14(4), 195-204. http://dx.doi.org/10.1177/026010600001400401

Landstrom, U., Knutsson, A., Lennernas, M., \& Stenudd, A. (2001). Onset of drowsiness and satiation after meals with different energy contents. Nutrition and Health, 15(2), 87-95. http://dx.doi.org/10.1177/026010600101500202

Liviya Ng, W., Freak-Poli R., Peeters A. (2014). The prevalence and characteristics associated with excessive daytime sleepiness among Australian workers. Journal of Occupational and Environmental Medicine, 56(9), 935-945. http://dx.doi.org/10.1097/JOM.0000000000000150

Locher, J. L., Robinson, C. O., Roth, D. L., Ritchie, C. S., \& Burgio, K. L. (2005). The effect of the presence of others on caloric intake in homebound older adults. The Journals of Gerontology. Series A, Biological Sciences and Medical Sciences, 60(11), 1475-1478. http://dx.doi.org/10.1093/gerona/60.11.1475

Mangialesche, F., Kivipelto, M., Mecocci, P., Rizzuto, D., Palmer, K., Winbald, B., \& Fratiglioni, L. (2010). High plasma levels of vitamin $\mathrm{E}$ forms and reduced Alzheimer's disease risk in advanced age. Journal of Alzheimer's Disease, 20(4), 1029-1037. http://dx.doi.org/10.3233/JAD-2010-091450

Matarese, L. E., \& Pories, W. J. (2014). Adult weight loss diets: Metabolic effects and outcomes. Nutrition in Clinical Practice, in press. http://dx.doi.org/10.1177/0884533614550251

Merriam-Webster (n.d.). Wellbeing. http://www.merriam-webster.com/dictionary/wellbeing

Neely, G., Landstrom, U., \& Bystrom, M. (2004). Missing a meal: Effects on alertness during sedentary work. Nutrition and Health, 18(1), 37-47. http://dx.doi.org/10.1177/026010600401800104 
Obisesan, T., Livingston, I., Trulear, H. D., \& Gillum, F. (2008). Frequency of attendance at religious services, cardiovascular disease, metabolic risk factors, and dietary intake in Americans: an agestratified exploratory analysis. International Journal of Psychiatry in Medicine, 36(4), 435-448. http://dx.doi.org/10.2190/9W22-00H1-362K-0279

Oliver, G., Wardle, J., \& Gibson, L. E. (2000). Stress and food choice: A Laboratory Study. Psychosomatic Medicine, 62(6), 853-865. http://dx.doi.org/10.1097/00006842-200011000-00016

Osler, M., Heitmann, B. L., Gerdes, L. U., Jorgensen, L. M., \& Schroll, M. (2001). Dietary patterns and mortality in Danish men and women: a prospective observational study. The British Journal of Nutrition, 85(2), 219-225. http://dx.doi.org/10.1079/BJN2000240

Osler, M., \& Schroll, M. (1997). Diet and mortality in a cohort of elderly people in a north European community. International Journal of Epidemiology, 26(1), 155-159. http://dx.doi.org/10.1093/ije/26.1.155

Payette, H., Gray-Donald, K., Cyr, R., \& Boutier, V. (1995). Predictors of dietary intake in a functionally dependent elderly population in the community. American Journal of Public Health, 85(5), 677-683. http://dx.doi.org/10.2105/AJPH.85.5.677

Polidori, C. M., Pratico, D., Mangialasche, F., Mariani, E., Aust, O., Anlasik, T., . . \& Gereon, N. (2009). High fruit and vegetable intake is positively correlated with antioxidant status and cognitive performance in healthy subjects. Journal of Alzheimer's Disease, 17(4), 921-927.

Requejo, A., Ortega, R., Robles, F., Navia, B., Faci, M., \& Aparicio, A. (2003). Influence of nutrition on cognitive function in a group of elderly, independently living people. European Journal of Clinical Nutrition, 57(Suppl 1), S54-S57. http://dx.doi.org/10.1038/sj.ejcn.1601816

Resnicow, K., Campbell, M. K., Carr, C., McCarty, F., Wang, T., Periasamy, S., . . \& Stables, G. (2004). Body and Soul A dietary intervention conducted through African-American churches. American Journal of Preventative Medicine, 27(2), 97-105. http://dx.doi.org/10.1016/j.amepre.2004.04.009

Roohafza, H., Sarrafzadegan, N., Sadeghi, M., Rafieian-Kopaei, M., Sajjadi, F., \& Khosravi-Boroujeni, H. (2013). The association between stress levels and food consumption among Iranian population. Archives of Iranian Medicine, 16(3), 145-148.

Ruel, G., Shi, Z., Zhen, S., Zuo, H., Kroger, E., Sirois, C., . . \& Taylor, A. W. (2013). Association between nutrition and the evolution of multimorbidity: The importance of fruits and vegetables and whole grain products. Clinical Nutrition, 33(3), 513-520. http://dx.doi.org/10.1016/j.clnu.2013.07.009

Sahyoun, N., \& Zhang, X. (2005). Dietary quality and social contact among a nationally representative sample of the older adult population in the United States. The Journal of Nutrition, Health \& Aging, 9(3), 177-183.

Small, G. W., Siddarth, P., Ercoli, L. M., Chen, S. T., Merrill, D. A., \& Torres-Gil, F. (2013). Healthy behavior and memory self-report in young, middle-aged, and older adults. International Psychogeriatrics, 25(6), 981-989. http://dx.doi.org/10.1017/S1041610213000082

Staessen, J., Amery, A., Birkenhager, W., Bulpitt, C., Clement, D., de Leeuw, P., . . \& Williams, B. O. (1990). Is a high serum cholesterol level associated with longer survival in elderly hypertensives? Journal of Hypertension, 8(8), 755-761. http://dx.doi.org/10.1097/00004872-199008000-00010

Steffen, L. M., Jacobs, D. R. J., Stevens, J., Shahar, E., Carithers, T., \& Folsom, A. R. (2003). Associations of whole-grain, refined-grain, and fruit and vegetable consumption with risks of all-cause mortality and incident coronary artery disease and ischemic stroke: The Atherosclerosis Risk in Communities (ARIC) Study. American Journal of Clinical Nutrition, 78(3), 383-390.

The National Institute of Wellness (n.d.). The six dimensions of wellness. http://www.nationalwellness.org/?page=Six Dimensions

Thomson, J. L., Zoellner, J. M., \& Tussing-Humphreys, L. M. (2014). Psychosocial predictors of diet and physical activity in African-Americans: Results from the Delta Body and Soul effectiveness trial, 2010-2011. American Journal of Health Promotion, 28(3), e81-91. http://dx.doi.org/10.4278/ajhp.120926QUAN-472

Torres, S. J., Lautenschlager, N. T., Wattanapenpaiboon, N., Greenop, K. R., Beer, C., Flicker, L., . . \& Nowson, C. A. (2012). Dietary patterns are associated with cognition among older people with mild cognitive impairment. Nutrients, 4(11), 1542-1551. http://dx.doi.org/10.3390/nu4111542 
U.S. Department of Commerce. (2010). Profile of General Population and Housing Characteristics: 2010. http://factfinder2.census.gov/faces/tableservices/jsf/pages/productview.xhtml?pid=DEC 10 DP DP $\underline{\mathrm{DP} 1}$

Valls-Pedret, C., Lamuela-Raventos, R. M., Medina-Remon, A., Quintana, M., Corella, D., Pinto, X., . . \& Ros, E. (2012). Polyphenol-rich foods in the Mediterranean diet are associated with better cognitive function in elderly subjects at high cardiovascular risk. Journal of Alzheimer's Disease, 29(4), 773-782.

Wang, L., Gaziano, M. J., Liu, S., Manson, J. E., Buring, J. E., \& Sesso, H. D. (2007). Whole- and refinedgrain intakes and the risk of hypertension in women. American Journal of Clinical Nutrition, 86(2), 472479.

Wells, A. S., Read, N. W., Idzikowski, C., \& Jones, J. (1998). Effects of meals on objective and subjective measures of daytime sleepiness. Journal of Applied Physiology, 84(2), 507-515.

Wengreen, H. J., Neilson, C., Munger, R., \& Corcoran, C. (2009). Diet quality is associated with better cognitive test performance among aging men and women. The Journal of Nutrition, 139(10), 1944-1949. http://dx.doi.org/10.3945/jn.109.106427

Wilcox, S., Parrott, A., Baruth, M., Laken, M., Condrasky, M., Saunders, R., . . \& Zimmerman, L. (2013). The Faith, Activity, and Nutrition Program A randomized controlled trial in African-American churches. American Journal of Preventative Medicine, 44(2), 122-131.

http://dx.doi.org/10.1016/j.amepre.2012.09.062

Woods, G., Levinson, A. H., Jones, G., Kennedy, R. L., Johnson, L. C., Tran, Z. V., . . \& Marcus, A. C. (2013). The living well by faith health and wellness program for African Americans: an exemplar of community-based participatory research. Ethnicity and Disease, 23(2), 223-229. 


\section{Appendix}

The relationship between dietary intake and the six dimensions of wellbeing in older adults

Table A - Intellectual wellness: The effects of dietary intake on memory in older adults

\begin{tabular}{|c|c|c|c|c|c|}
\hline $\begin{array}{c}\text { Author \& } \\
\text { year }\end{array}$ & Objective & Design & Results & Statistics & $\begin{array}{l}\text { Confounders } \\
\text { adjusted for }\end{array}$ \\
\hline $\begin{array}{l}\text { Requejo et } \\
\text { al., } 2003\end{array}$ & $\begin{array}{l}\text { A prospective } \\
\text { analysis of non- } \\
\text { institutionalized } \\
\text { elderly adults in } \\
\text { Spain examined } \\
\text { dietary intake and } \\
\text { cognitive } \\
\text { function. }\end{array}$ & $\begin{array}{l}\text { *168 adults, age } 65-90 y o \text {, } \\
\text { without significant cognitive } \\
\text { impairment } \\
\text { * } 7 \mathrm{~d} \text { food records, and also } 5 \mathrm{~d} \\
\text { precise weighing of midday } \\
\text { meal at day centers where } \\
\text { lunch was consumed } \\
\text { *Diets were compared to } \\
\text { recommended intakes for the } \\
\text { Spanish population (RI) to } \\
\text { assess adequacy of diet } \\
{ }^{*} \text { MMSE measured cognitive } \\
\text { function ( } \geq 28 \text { is satisfactory, } \\
<28 \text { is unsatisfactory) } \\
\text { *Subjects grouped based on age; } \\
<75 y o \text { or } \geq 75 y o\end{array}$ & $\begin{array}{l}{ }^{*} \text { MMSE scores were worse in } \\
\text { older age } \\
{ }^{*} \text { Overall food intake, fish intake } \\
\text { and alcohol intake were higher in } \\
\text { subjects with satisfactory MMSE } \\
\text { scores } \\
\text { *"Various" foods (i.e.: chocolates } \\
\text { and sweets) were lower in those } \\
\text { with satisfactory MMSE scores } \\
\text { *Saturated fat, MUFA and } \\
\text { cholesterol intakes were lower in } \\
\text { subjects with satisfactory MMSE } \\
\text { scores } \\
\text { *Thiamin, folate and vitamin C } \\
\text { intakes were higher in subjects } \\
\text { with satisfactory MMSE } \\
\text { *Alcohol intake positively related } \\
\text { to MMSE scores }\end{array}$ & $\begin{array}{l}\text { Total food (g/d) (mean(SD)) in MMSE } \geq 28 \\
\text { for younger and older subjects, respectively: } \\
1622(379) \text { and } 1611(376) \text {. Total food (g/d) } \\
\text { (mean(SD)) in MMSE }<28 \text { for younger and } \\
\text { older subjects, respectively: } 1442(311) \text { and } \\
\text { 1522(309). Fish intake (g/d) (mean(SD)) in } \\
\text { MMSE } \geq 28 \text { for younger and older subjects, } \\
\text { respectively:103.4(72.9) and } 105.0(56.0) \text {. Fish } \\
\text { intake (g/d) (mean(SD)) in MMSE }<28 \text { for } \\
\text { younger and older subjects, respectively: } \\
\text { 101.4(76.4) and } 54.5(44.8) \text {. Alcohol intake } \\
\text { (g/d) (mean(SD)) in MMSE } \geq 28 \text { for younger } \\
\text { and older subjects, respectively:48.4(104.9) } \\
\text { and } 52.8(105.4) \text {. Alcohol intake (g/d) } \\
\text { (mean(SD)) in MMSE }<28 \text { for younger and } \\
\text { older subjects, respectively:15.9(46.6) and } \\
\text { 12.3(44.2). Various food intake (g/d) } \\
\text { (mean(SD)) in MMSE } \geq 28 \text { for younger and } \\
\text { older subjects, respectively: } 20.8(34.6) \text { and } \\
\text { 16.5(21.1). Various food intake (g/d) } \\
\text { (mean(SD)) in MMSE <28 for younger and } \\
\text { older subjects, respectively: } 29.4(35.2) \text { and } \\
38.1(46.0) \text {. Mean (SD) intake of lipids } \\
\text { (density, g/4184kJ) in MMSE } \geq 28 \text { for younger } \\
\text { and older subjects, respectively: } 41.3(8.4) \\
\text { and 39.2(8.7). Mean (SD) intake lipids } \\
\text { (density, g/4184kJ) in MMSE }<28 \text { for younger } \\
\text { and older subjects, respectively: } 43.0(7.6) \\
\text { and } 44.5(8.7) \text {. Mean (SD) intake of saturated } \\
\text { fat (density, g/4184kJ) in MMSE } \geq 28 \text { for }\end{array}$ & None provided \\
\hline
\end{tabular}


younger and older subjects, respectively:

12.5(3.8) and 12.4(4.2). Mean (SD) intake of saturated fat (density, $\mathrm{g} / 4184 \mathrm{~kJ}$ ) in

MMSE $<28$ for younger and older subjects, respectively: 13.5(2.9) and 14.8(3.5). Mean (SD) intake of MUFA (density, $\mathrm{g} / 4184 \mathrm{~kJ}$ ) in MMSE $\geq 28$ for younger and older subjects, respectively: 19.0(4.4) and 18.3(4.0). Mean (SD) intake of MUFA (density, g/4184kJ) in MMSE $<28$ for younger and older subjects, respectively: 20.2(5.2) and 20.2(3.9). Mean (SD) intake of cholesterol (density, g/4184kJ) in MMSE $\geq 28$ for younger and older subjects, respectively: 185.1(75.4) and 182.5(53.3). Mean (SD) intake of cholesterol (density, $\mathrm{g} / 4184 \mathrm{~kJ}$ ) in MMSE $<28$ for younger and older subjects, respectively: 200.9(67.9) and 224.7(108.6). Mean (SD) intake of thiamin $(\mathrm{mg} / \mathrm{d})$ in MMSE $\geq 28$ for younger and older subjects, respectively: $1.12(.34)$ and 1.12(.44). Mean (SD) intake of thiamin (mg/d) in MMSE $<28$ for younger and older subjects, respectively: 1.05(.29) and .96(.23). Mean (SD) intake of folate (microgram/d) in MMSE $\geq 28$ for younger and older subjects, respectively: 202.0(73.7) and 222.9(113.8). Mean (SD) intake of folate (microgram/d) in MMSE $<28$ for younger and older subjects, respectively: $182.9(60.5)$ and $180.5(64.3)$. Mean (SD) intake of vitamin C (mg/d) in $M M S E \geq 28$ for younger and older subjects, respectively: 134.5(78.4) and 137.6(78.3). Mean (SD) intake of vitamin C (mg/d) in MMSE $<28$ for younger and older subjects, respectively: 103.6(60.6) and 105.4(45.9)

*Adjusted mean intakes for fatty fish, DHA and EPA were higher in
Adjusted mean EPA and DHA combined (mg), and fatty fish intake (g) for normal
Age, sex,

education, total 
from the

Doetinchem

Cohort Study

examined dietary

intake and

cognition.
Polidori et An observational al., 2009 study examined the relationship between antioxidant status and cognition in older adults.
${ }^{*}$ Questionnaires assessed sociodemographics, education level, health history, and alcohol use *Non-fasting blood samples assessed HDL cholesterol *Global cognition, memory, speed of cognitive process, and cognitive flexibility assessed with the (Visual) Verbal Learning Test, an abbreviated Stroop Color Word Test, the Concept Shifting Task, the Letter Digit Substitution Test, and a Category Fluency Test

*193 adults ( $m=93, f=100)$, mean age 70.8 yo

*FFQ assessed dietary intake ${ }^{*} \mathrm{Ht}$, wt, ECG, BP, lab values

(lipid, albumin) measured *BMI calculated

*MMSE, Clock Drawing Test assessed cognition

${ }^{*}$ DemTect Scale assessed

dementia

*Education and lifestyle

questions answered

*Subjects divided into high $\mathrm{f} \& \mathrm{v}$ intake (HI=4+servings/d) and

low intake ( $\mathrm{LI}=1$ or fewer servings/d) subjects with normal cognition compared to those with impaired cognition

*Higher dietary cholesterol intake was positively and significantly associated with risk for impaired memory and flexibility

${ }^{*}$ Cognitive function and the overall intake of total PUFA linoleic acid, alpha-linoleic acid, and MUFA demonstrated no relationship

*Better antioxidant micronutrient status and lower levels of lipid peroxidation and protein oxidation (measures of oxidative stress) in HI subjects

*Better cognitive performance in

HI compared to LI subjects

regardless of age (higher scores in

Clock Drawing indicate more

errors, or poorer results)

${ }^{*}$ Lycopene strongly correlated

with all cognitive performance

tests

*Alpha-tocopherol associated with MMSE and Clock Drawing Test scores

*MMSE negatively associated with biomarkers of oxidative stress

*Subjects consuming 5 + servings of $f \& v$ per day demonstrated higher antioxidant micronutrients and lower indicators of oxidative stress, and demonstrated better cognition $(95 \% \mathrm{CI})=167(160-175)$ and 3.06

(2.85-3.28), respectively. Adjusted mean EPA and DHA (mg), and fatty fish intake $(\mathrm{g})$ for impaired cognition $(95 \% \mathrm{CI})=145$ (124-166) and 2.30 (1.68-2.93). Dietary cholesterol and impaired memory risk $(95 \% \mathrm{CI})$ :

$\mathrm{OR}=1.27(1.02-1.57), \mathrm{p}<.05$; dietary cholestero and impaired flexibility risk: $\mathrm{OR}=1.26(1.01$ 1.57), $\mathrm{p}<.05$. DHA and EPA intake and risk of impaired overall cognition and speed (95\%CI, p<.05): OR=.81(.66-1.00) and $\mathrm{OR}=.72(.57-.90)$, respectively.

HI subjects mean MMSE, DemTect and Clock Drawing $=29.4,16.8$, and 1.02 respectively. LI subjects mean MMSE, DemTect and Clock Drawing=28.5, 16.2, and 1.38, respectively. Lycopene was associated with MMSE ( $r=0.22, \mathrm{p}=.005)$, DemTect $(\mathrm{r}=0.19, \mathrm{p}=.02)$, and Clock Drawing $(\mathrm{r}=0.35$, $\mathrm{p}<.0001)$. MMSE and Clock Drawing were associated with alpha-tocopherol $(\mathrm{r}=0.22$, $\mathrm{p}=.003$; and $\mathrm{r}=-0.26, \mathrm{p}<.0001) .8,12-\mathrm{IPF}$ 2alpha-VI and IgG of protein carbonyls both negatively correlated with MMSE $(\mathrm{r}=-0.23$, $\mathrm{p}=.007$; and $\mathrm{r}=-0.17, \mathrm{p}=0.04$, respectively). energy intake smoking, and risk of CVD

Age, gender, BMI, education, total cholesterol LDL and HDL

cholesterol, triglycerides and albumin 
Berr et al., An observational 2009 epidemiological cohort examined olive oil intake and cognitive function in older adults.

A prospective study examined the association

between recommended food score (RFS) and non-RFS, and cognitive function
*6,947 free-living adults, $65+$ yo ${ }^{*} \mathrm{FFQ}$ assessed dietary intake *4y follow-up

*MMSE assessed global cognitive function

*Isaacs Set Test measured verbal fluidity and speed of verbal production

*Benton Visual Retention Test measured visual memory

* 3,634 adults, mean age 74yo ${ }^{*} 11$ y follow-up

*FFQ assessed dietary intake *3MS assessed cognitive function, including memory *RFS was computed based on Dietary Guidelines for

Americans (f\&v, whole grains, nuts, fatty fish, low-fat dairy)

*Questionnaires included

lifestyle and socio-demographic info cognitive functioning compared to those consuming only one serving per day

*Olive oil consumption was higher in subjects with higher education level

*Subjects with moderate to high olive oil consumption

demonstrated lower risk of cognitive decline in visual memory and verbal fluency *Olive oil consumption not associated with MMSE

*Intensive olive oil use associated with a $15 \%$ reduction in verbal fluency decline and $17 \%$ reduction in visual memory decline *Inverse relationship between PUFA and MMSE

*Mean 3MS increased across increasing RFS quartiles ${ }^{*}$ Cognitive function declined less in those with higher RFS than those with lower RFS scores

*Following the Dietary Guidelines for Americans was associated with lower levels of cognitive decline

11

Cognitive decline (\%) for Global Cognitive Function associated with olive oil use ( $\mathrm{p}$ value $=.37$ ): non-users $=14.9 \%$, intensive users $=13.3 \%$; Cognitive decline for verbal fluency $(\%)$ ( $p$-value $=.3$ ): non-users $=16.6 \%$, intensive users $=14.8 \%$; Cognitive decline for cognitive function for visual memory ( $\mathrm{p}$ value $=.01$ ): non-users $=21.4 \%$, intensive users $=17.8 \%$. Fully adjusted OR $(95 \% \mathrm{CI})$ for olive oil use and global cognitive decline (no use=reference for all categories): moderate use: .94(.78-1.13), intensive use: .95(.78-1.15). Fully adjusted OR (95\%CI) for olive oil use and verbal fluency decline: moderate use: .96(.80-1.16), intensive use: .85(.70-1.03).

Fully adjusted OR (95\%CI) for olive oil use and visual memory decline: moderate use: .91(.77-1.09), intensive use: .83(.69-.99)

Mean cumulative decline in 3MS (SE) from baseline to follow up based on quartiles of RFS: Baseline ( $\mathrm{n}=3,634)$ : $\mathrm{Q} 10 \mathrm{y}=0$ (reference), $\mathrm{Q} 2=.94(.26), \mathrm{Q} 3=1.48(.28), \mathrm{Q} 4=1.80(.28) ; 3 \mathrm{y}$ follow-up (n=2,743): Q1=-1.14(.39), Q2=-

.64(.60), Q3=-.81(.38), Q4=-.41(.36). 7y followup (n=1,907): Q1=-2.96(.64), Q2=-2.02(.66), $\mathrm{Q} 3=-2.51(.66), \mathrm{Q} 4=-1.56(.65)$. 11y follow-up: Q1=-5.15 (.69); Q2=-3.98(1.08); $\mathrm{Q} 3=-4.91(1.08) ; \mathrm{Q} 4=-3.41(.79)$
Gender, age, study center, income, education, baseline cognitive score, health behavior, health status, dietary habits, and smoking status

Age, gender, education, BMI APOE e4 allele, smoking status, drinking status, activity level, medical history, ability to perform ADLs,

vitamin/mineral supplement use, caloric intake,

time $x$ time and interactions between time 
Mangialasc A nested

he et al.,

2010
*232 adults, age $80+y o$, all in non-demented state at baseline observational study of subjects from the larger Kungsholmen Project, examined the relationship between baseline plasma

concentrations of natural vitamin $\mathrm{E}$ forms and incidence of Alzheimer's disease.

* Questions on age, gender,

alcohol consumption,

education, vitamin and

supplement use, and smoking habits answered

${ }^{*}$ MMSE assessed cognitive

function

${ }^{*}$ Katz index of ADLs assessed

basal functional status

${ }^{*} \mathrm{Ht}$ and wt measured and BMI calculated

*Blood samples assessed DNA

APOE, and presence of the eight natural forms of vitamin
being measured (alpha, beta,

delta and gamma tocopherols,

and alpha, beta, delta and

gamma tocotrienols)

${ }^{*}$ Cognitive function assessed at

baseline and follow ups, up to

$6 y$ past baseline

Clinical and

neuropsychological evaluations

were conducted at baseline and

follow-ups

*Dementia and/or AD

diagnosed by two different

physicians

*Plasma vitamin E measures

levels assessed objective

vitamin E exposure
*Development of AD was more common in older subjects

*All forms of vitamin E were

lower in subjects who developed

$\mathrm{AD}$, but this difference lacked

statistical significance

*Subjects in the highest tertile of

total tocopherols, tocotrienols, or

vitamin $\mathrm{E}$ levels had reduced risk

of developing AD (reduced by

$45 \%, 54 \%$, and $45 \%$, respectively)

when compared to subjects in the lowest tertile

*Beta-tocopherol associated with

$\mathrm{AD}$ risk when comparing highest

tertile with the lowest.
Incident cases and $\mathrm{HR}(95 \% \mathrm{CI})$ of $\mathrm{AD}$ by vitamin $\mathrm{E}$ plasma levels at baseline: total tocopherols lowest tertile: 18 cases, $\mathrm{HR}=1$ (reference); total tocopherol highest tertile: 11 cases, HR=.55(.32-.94); total tocotrienols lowest tertile: 15 cases, $\mathrm{HR}=1$ (reference); total tocotrienols highest tertile: 9 cases, $\mathrm{HR}=.46(.23-.92)$; total vitamin $\mathrm{E}$ lowest tertile: 18 cases, $\mathrm{HR}=1$ (reference); total vitamin $\mathrm{E}$ highest tertile: 11 cases, $\mathrm{HR}=.55(.32-.94)$ and increasing quintile of RFS Age, gender, BMI, baseline MMSE scores, education, APOE status, alcohol use and smoking status 
Krikorian et A double-blind al., 2010 randomized,

${ }^{*} 12$ adults $(\mathrm{m}=8, \mathrm{f}=4)$, mean age of $78.2 \mathrm{yo}$

controlled trial

examined

Concord grape

consumption and

association with

memory in older

adults.

Valls-Pedret A cross-sectional et al., 2012 study of

participants from

the PREDIMED

cohort examined

dietary intake,

with a focus on

polyphenols, as it

pertains to

cognitive
*Subjects had memory lapses and forgetfulness, but no diagnosis of dementia at

baseline

*12-week duration

${ }^{*}$ Control $(n=5)$ consumed

concord grape juice and

placebo $(n=7)$ consumed drink

with equivalent energy and

carbohydrate content. Amount

of beverage provided was 6

$9 \mathrm{ml} / \mathrm{kg}$ body wt per day,

divided into three equal

servings

*Clinical Dementia Ratings

assessed memory impairment

${ }^{*}$ CVLT assessed Verbal learning

and retention

*SPA Learning Test assessed

non-verbal memory

*The Geriatric Depression Scale assessed mood

*Wt, waist circumference, and

fasting serum glucose and

insulin levels measured

*447 adults $(\mathrm{m}=215, \mathrm{f}=232), 55$ 80 yo,

*Subjects at high cardiovascular disease risk, but without

chronic illness, drug/alcohol

abuse, depression, or BMI $>40$

${ }^{*}$ FFQ assessed dietary intake

${ }^{*} \mathrm{Ht}$ and wt measured

*Urine samples assessed total polyphenols
*Grape juice consumption was associated with improved

memory

*CVLT scores improved from baseline to week 12 for the grape juice group (35.2 points to 38.6) *No improvement in CVLT scores in placebo subjects

*Non-significant trend toward improved performance in spatial memory and delayed verbal recall in grape juice group

*Insulin levels increased

significantly in the grape juice group (from $9.6 \mathrm{micro}-\mathrm{U} / \mathrm{ml}$ to 12.6)

${ }^{*}$ No change in insulin levels in placebo group

Based on FFQ, most subjects adhered to a traditional

*Higher wine intake associated with better MMSE scores

*Olive oil consumption associated with improved immediate verbal memory
CVLT item acquisition performance:

Individual

$\mathrm{F}(1,8)=5.55, \mathrm{p}=.04, \mathrm{f}=.28$; CVLT delayed recall differences

: $\mathrm{F}(1,8)=3.37, \mathrm{p}=.1, \mathrm{f}=.35$; SPA (non-verbal

memory): $\mathrm{F}(1,8)=3.23, \mathrm{p}=.12, \mathrm{f}=.67$
Independent association of cognitive scores with food intake $(b=$ standardized regression coefficient; 95\%CI): wine and MMSE: .252

(.006-.496), $\mathrm{b}=.096, \mathrm{p}=.044$; olive oil and RAVLT immediate recall: .755(.151-1.358), $\mathrm{b}=109, \mathrm{p}=.014$; cereal and RAVLT

immediate: $-.431(-.823$ to -.038$), b=-.098$, $\mathrm{p}=.032$; cereal and RAVLT delayed: -.235 (.379 to -.091$), \mathrm{b}=-.149, \mathrm{p}=.001$; coffee and RAVLT delayed: .294(.055-.534), $\mathrm{b}=.106$,
Variables allowed for associations with cognitive test scores with food intake: age, education, gender, BMI, APOE, smoking, energy expended 
functioning in older subjects.

Torres et al., A cross-sectional 2012 analysis of older adults with mild cognitive impairment examined the association between dietary patterns, physical activity, and cognition.
*RAVLT assessed verbal memory

*WMS assessed memory performance

*WAIS assessed immediate memory and working memory *Color Trail Test assessed executive functioning (attention, visual-motor speed and cognitive flexibility

*MMSE assessed global cognitive function

*249 subjects $(\mathrm{m}=155, \mathrm{f}=94)$, mean age $73.4 y o$ * Subjects had mild cognitive impairment but no clinical diagnosis of dementia *FFQ assessed dietary intake *CAMCOG assessed global cognitive function

*Dietary patterns categorized as whole foods (f\&v, legumes, whole grain, fish, egg, low-fat dairy, nuts and salad dressings) and processed foods (saturated

fats, desserts/sweets/fried foods, chocolates and sweets, processed meat and fish, highfat dairy, potatoes, refined grain, sugary drinks, and red meat)

Small et al., An observational 2013 analysis examined the relationship between healthy behaviors and ${ }^{*} 18,552$ subjects

* Subjects were divided by age: younger adults (18-39yo, $n=4,423)$, middle-aged (40-59yo, $\mathrm{n}=6,356)$ and older adult $(60$ 99 yo, $n=7,773$ )
*Cereal intake negatively associated with immediate and delayed recall of verbal learning *Coffee intake associated with better delayed recall

*Meat associated with worse delayed recall

*Walnuts associated with better working memory

*Total urine polyphenol excretion associated with immediate verbal recall

*Whole foods pattern not associated with CAMCOG scores

*Processed food pattern negatively associated with CAMCOG scores

${ }^{*}$ Executive function scores processed food pattern

*Subjects consuming more processed foods had reduced memory and impaired executive function

${ }^{*}$ Mean HBI was 69.8 for older adults, 60.7 for middle-aged (60.7), and 57.9 for younger adults *Older adults more likely "eating five or more daily servings of fruits and vegetables during the negatively associated with $\mathrm{p}=.016$; meat and RAVLT delayed: -.845 (-

1.556 to -.135$), \mathrm{b}=-.109, \mathrm{p}=.020$; walnuts and reverse digit span: 1.191 (.061-2.322), $\mathrm{b}=.149$ $\mathrm{p}=.039$. Independent associations of cognitive scores with urinary polyphenol excretion $(b=$ standardized regression coefficient; 95\%CI): polyphenol excretion and RAVLT immediate: 1.208(.236-2.180), $\mathrm{b}=.112, \mathrm{p}=.015$; polyphenol excretion and RAVLT delayed: .357 (-.004-.719), b=.092, $\mathrm{p}=.053$

Total CAMCOG score by tertile of processed food pattern, fully adjusted $(\mathrm{OR}(95 \% \mathrm{CI}))$ : T1 (reference) $=1 ; \mathrm{T} 2=1.51$ (.69-3.33), $\mathrm{p}$ value $=.303 ; \mathrm{T} 3=1.70$ (.76-3.79), $\mathrm{p}$-value comparing T3 with $\mathrm{T} 1=.199$, $\mathrm{p}$ for trend $=.211$ CAMCOG executive scales, fully adjusted (OR(95\%CI)): T1=1 (reference); T2=1.57 (.663.71), p-value=.095; T3=2.55 (1.08-6.03), p value comparing $\mathrm{T} 1$ with $\mathrm{T} 3=.033$, $\mathrm{p}$ for trend $=.030$.

in physical activity, diabetes, ypertension and hyperlipidemia Association of cognitive test scores with urinary excretion controlled also included energy intake.

Age, gender, smoking, education, activity, antidepressant

Effect size (d) for HBI scores and age: older vs. middle-aged: $\mathrm{d}=.38$ (small); older vs. younger: $\mathrm{d}=.42$ (small); middle-aged vs. younger: $d=.09$ (small). Effect size for HBI scores and memory: younger: $\mathrm{d}=.26$; middleaged: $\mathrm{d}=.30$; older: $\mathrm{d}=.25$. Odds ratio for $\%$ of
Education and income 
self-reported memory abilities in adults.

\section{Bookheimer A placebo-} et al., 2013 controlled, randomized clinical trial examined the relationship between pomegranate juice consumption and memory performance and fMRI activity in adults.
${ }^{*} \mathrm{HBI}$ assessed 4 components and a score of 0 (not complying) or 1 (complying with the healthy behavior) was assigned for each

*HBI behaviors included: 1) Do you smoke?; 2) Did you eat healthy all day yesterday?; 3) In the last 7 days, on how many days did you have 5 or more servings of $f \& v$ ?; 4) In the last 7 days, on how many days did you exercise for 30 or more minutes?

*Data was weighted to match age, sex, region, education, ethnicity and race according to information from the US Census Bureau

*28 adults, age 55+yo,

*Subjects non-demented but had mild, age-related memory complaints

*28d intervention

*All subjects placed on low-

polyphenol diet and instructed to maintain a sedentary lifestyle aside from light walking during the trial

*Intervention subjects $(\mathrm{n}=15)$ provided with $80 z$ of pomegranate juice per day ${ }^{*}$ Control subjects $(\mathrm{n}=13)$ provided with $8 \mathrm{oz}$ of a placebo drink per day

*Antioxidant assays assessed metabolites of the juice previous week" (64\%) and of

"eating healthy yesterday" (84\%) than middle aged $(53.9 \%$ and $65.8 \%$, respectively) and younger adults $(49.1 \%$ and $56.2 \%$,

respectively)

*Memory problems reported more frequently as age increased

*Memory problems negatively associated with HBI scores (mean HBI 60.9 in those reporting memory problems, and 66.2 in those who did not)

*HBI healthy behavior adherence inversely related to odds of reporting memory problems ${ }^{*}$ Healthy eating associated with improved memory in all age groups

*Plasma biomarkers for antioxidants were higher in the pomegranate group than the control at the end of the study

*Total recall and long-term retrieval scores improved significantly in the pomegranate group, compared to controls ${ }^{*}$ No significant improvement or change within or between groups for both visual and verbal

memory

*The pomegranate group recruited more brain regions and had more fMRI activation in all regions than the placebo group healthy behavior adherence $(1=25 \%, 2=50 \%$, $3=75 \%$ or $4=100 \%$ ) and reporting memory problems $(95 \% \mathrm{CI}): 0 \%$ : OR=2.11(1.85-2.41); $25 \%$ : OR=1.75(1.59-1.93); 50\%: OR=1.45(1.36$1.55) ; 75 \%=1.21(1.17-1.25)$

TEAC in juice vs. placebo from baseline to $28 \mathrm{~d}$ measures (unpaired $\mathrm{t}$-test): $\mathrm{t}=2.8, \mathrm{df}=25$, $\mathrm{p}<.05$. Memory performance improvement from baseline to $28 \mathrm{~d}$ (2-tailed t-test) in placebo subjects: $\mathrm{t}=1.1, \mathrm{p}>.3$; in juice subjects: $\mathrm{t}=2.8, \mathrm{p}=.017$. $\mathrm{fMRI}$ activation of all regions for pomegranate juice $>$ placebo (all regions): Z-stat range from 2.6-4.23 ( $\mathrm{Z}>2.0$, corrected $\mathrm{p}=.05$ ) 
*Bushke-Fuld selective

reminding task and consistent

long term retrieval score

assessed memory

*Verbal and visual memory

tasks completed

*fMRI assessed brain activity

during memory exercises

Note: MMSE=Mini-mental state examination, $\mathrm{SD}=$ standard deviation, HDL=high-density lipoprotein, $\mathrm{DHA}=$ docosahexaenoic acid, EPA= eicosapentaenoic acid, $\mathrm{PUFA}=$ polyunsaturated fatty acids, MUFA=mono-unsaturated fatty acid, CI=confidence interval, ht=height, wt=weight, BP=blood pressure, ECG=electrocardiogram, BMI=body mass index, 3MS=Modified Mini-Mental State Examination, RFS=recommended food score, f\&v=fruits and vegetables, APOE=apolipoprotein E, ADL=activities of daily living, AD=Alzheimer's disease, HR=hazard ratio, CVLT= California Verbal Learning Test, SPA=Spatial paired associate, RAVLT=Rey auditory verbal learning test, WMS=Wechsler Memory Scale, WAIS=Wechsler Adult Intelligence Scale, CAMCOG= Cambridge Cognitive Examination, OR=odds ratio, HBI=Healthy Behavior Index, fMRI=functional magnetic resonance imaging, TEAC=trolox-equivalent antioxidant capacity

Table B - Occupational wellness: The effects of dietary intake on daytime sleepiness in older adults

\begin{tabular}{|c|c|c|c|c|c|}
\hline $\begin{array}{c}\text { Author \& } \\
\text { year }\end{array}$ & Objective & Design & Results & Statistics & $\begin{array}{l}\text { Confounders } \\
\text { adjusted for }\end{array}$ \\
\hline $\begin{array}{l}\text { Wells et al., } \\
1998\end{array}$ & $\begin{array}{l}\text { The effects of } \\
\text { high-fat, low } \\
\text { carbohydrate and } \\
\text { low-fat, high } \\
\text { carbohydrate } \\
\text { meals on objective } \\
\text { daytime } \\
\text { sleepiness were } \\
\text { examined. }\end{array}$ & $\begin{array}{l}{ }^{*} 16 \text { adults }(\mathrm{m}=8, \mathrm{f}=8) \text {, age } \\
\text { unspecified } \\
\text { *Participants were randomized } \\
\text { to Group } 1 \text { (meals eaten at 9am } \\
\text { and } 1 \mathrm{pm} \text { ) or Group } 2 \text { (meals } \\
\text { eaten at } 11 \mathrm{am} \text { and } 3 \mathrm{pm} \text { ) } \\
{ }^{*} \text { Measurements taken on two } \\
\text { separate days, with meals } \\
\text { presented in opposite order } \\
\text { each day } \\
{ }^{*} \text { Sleep patterns regulated by } \\
\text { encouraging subjects to go to } \\
\text { bed and get up in the morning } \\
\text { at the same times for a week } \\
\text { prior to the study } \\
{ }^{*} \text { EEG measured brain activity } \\
\text { for objective sleepiness }\end{array}$ & $\begin{array}{l}\text { *Less time to achieve sleepiness } \\
\text { after a meal as opposed to before } \\
\text { *Sleep latency didn't differ based } \\
\text { on meal composition or time of } \\
\text { day } \\
\text { *Sleep latency significantly shorter } \\
1.5 \mathrm{~h} \text { after eating than it was just } \\
\text { before meals } \\
\text { *Subjects more sleepy in the later } \\
\text { part of the day based on EEG } \\
\text { measures, with little difference } \\
\text { between pre and post meal } \\
\text { measures } \\
\text { *EEG activity over } 3 \text { hours after } \\
\text { meal ingestion indicated more } \\
\text { sleepiness as compared to } 80 \\
\text { minutes after ingestion or to pre- } \\
\text { meal measures }\end{array}$ & $\begin{array}{l}\text { Mean sleep latency } 1.5 \mathrm{~h} \text { after meals: } 12.6 \\
(\mathrm{SD}=3.8) \text { and pre-meal: } 14.3(\mathrm{SD}=4.1) \\
\mathrm{F}=11.37, \mathrm{df}=1,15, \mathrm{p}=.004 . \text { Power of } \mathrm{EEG} \text { alpha } \\
\text { band later in day: } \mathrm{F}=12.52, \mathrm{df}=1,15, \mathrm{p}=.003 \\
\text { and earlier in the day: } \mathrm{F}=11, \mathrm{df}=1,15, \mathrm{p}=.005)\end{array}$ & None provided \\
\hline
\end{tabular}


*Stanford Sleepiness Scale, a and POMS assessed subjective sleepiness and mood

*Performance assessed using a high-paced task demanding continuous attention

*11 male truck drivers, age

Landstrom
et al., 2000

A controlled crossover trial of truck drivers

examined

whether the

proportion of fat and

carbohydrates in

meals with equal

energy content

would affect

wakefulness

during driving. 5 day drivers

${ }^{*}$ High fat meal (46\% of energy from fat and $43 \%$ from

carbohydrates) vs. low fat meal (18\% of energy from fat and $70 \%$ from carbohydrates)

examined

* Subjects answered questions regarding wakefulness while driving

*Drivers consumed meals and VAS, mood adjective checklist,

*Performance and overall feelings of fatigue increased and vigor and energy decreased throughout the day, with subjects feeling less

vigorous 45 -minutes after

ingestion than they did prior to eating

* Meals consumed between 11am and $3 \mathrm{pm}$ resulted in the highest rate of postprandial sleepiness

* Objective and subjective

measures did not demonstrate

significant difference between effect of meal types (LFHC vs. HFLC) and sleepiness

*Prior to intervention, day drivers unspecified, 6 night drivers and slept on average $1 \mathrm{~h}$ more than completed questionnaires during work shifts, from $5 \mathrm{pm}-$

3am (dinner and snack) for night drivers and $6 \mathrm{am}-4 \mathrm{pm}$ (breakfast and lunch) for day drivers

*Five tests total were completed on each group

*Day drivers reported lower levels of wakefulness while driving than night drivers

*Napping patterns throughout the shifts were not associated with

meal content

${ }^{*}$ No statistical difference between

macronutrient content of meals

(high fat vs. low fat) and

wakefulness in either group
No statistically significant results provided. None provided. See Results section for study outcomes. 
Landstrom Effects of energy

et al., 2001

content and

volume on

satiation and

alertness were

examined.

Grandner et The relationship

al., 2010

between various
*10 subjects $(\mathrm{m}=5, \mathrm{f}=5), 18-64$ yo *Varying energy content tested $(100,500$, and $1000 \mathrm{kcal})$

*Varying volume tested

(100kcal and $0 \mathrm{~mL}$ water vs.

$100 \mathrm{kcal}$ and $925 \mathrm{~mL}$ water)

* Subjects were sleep deprived

(4 hours or less the previous

night) and were in a fasted state

*Meals contained bread, butter

( $80 \%$ fat) and cheese ( $28 \%$ fat)

in varying quantities but equal

$\%$ of energy from each for 4

different meals

${ }^{*}$ Questionnaire completed for

overall health and for eating

and sleeping patterns

*5-minute blinking reference

test and 30min EEG assessed

objective sleepiness

*Subjective alertness assessed

with verbal rating and VAS

every $5 \mathrm{~min}$

*Subjective hunger satiation

rating on 1-4 categorical scale every $10 \mathrm{~min}$

*423 women, mean age 68 yo

${ }^{*} \mathrm{FFQ}$ assessed dietary intake

nutrients and

sleep patterns

was examined in

post-menopausal

women.

*Subjective sleep based on 1wk sleep diary

*Objective sleep based on wris

acti-graph worn for $1 \mathrm{wk}$
*Equally reduced subjective

drowsiness after consumption of

all meals

*Drowsiness increased after

consumption to return to pre-

consumption levels for all meals

*90-min post-consumption

development of subjective and

objective drowsiness similar for al

meals

*Water and caffeine negatively associated with subjective
Reduced subjective drowsiness on VAS after consumption: $\mathrm{F}=52.7, \mathrm{p}<.001$. Subjective

drowsiness for all 4 food condition

immediate post-consumption: $\mathrm{F}=.94, \mathrm{p}=.47$.

Effect of subjective drowsiness development

in 90-min post ingestion: horizontal scale effect of food: $\mathrm{F}=2.27, \mathrm{p}=.11$; horizontal scale effect of time: $\mathrm{F}=12.0, \mathrm{p}<.001$; Food $\mathrm{x}$

Time $=.93, \mathrm{p}=.62$

None provided

napping

${ }^{*}$ Top 5 most strongly associated

nutrients with subjective napping:

Total fat, calories, saturated fat,

MUFA and trans fat

${ }^{*}$ Objective sleep duration

negatively associated with total,

MUFA, saturated, PUFA and trans

fats, calories, gamma-tocopherol,
Partial correlation of nutrients and

subjective napping ( $\mathrm{p}$ for significance $<.004$ ) total fat: $\mathrm{r}=.241, \mathrm{p}=.000003$; calories: $\mathrm{r}=.238$,

$\mathrm{p}=.000004$; saturated fat: $\mathrm{r}=.237, \mathrm{p}=.000004$;

MUFA: $r=.231, \mathrm{p}=.00001$; trans fat: $\mathrm{r}=.230$, $\mathrm{p}=.00001$. Partial correlation of nutrients and objective sleep duration ( $\mathrm{p}$ for significance <.004): total fat: $r=-.185, \mathrm{p}=.0004$; MUFA: $r=-$ $180, \mathrm{p}=.0005$; trans fat: $\mathrm{r}=-.174, \mathrm{p}=.0008$;

saturated fat: $r=-.171, \mathrm{p}=.0010$; PUFA: $r=-.168$ $\mathrm{p}=.0012$; calories: $\mathrm{r}=-.162, \mathrm{p}=.0019$; gamma-
Age, education

income, BMI,

physical activity, daily food

consumption (g) 
cholesterol and alpha-tocopherolequivalents

*Vitamin D positively associated

with later peak sleep time tocopherol: $\mathrm{r}=-.157, \mathrm{p}=.0025$; alpha-

tocopherol-eq: $r=-.153, p=.0032$; cholesterol:

$\mathrm{r}=-.157, \mathrm{p}=.0025$. Partial correlation of

vitamin $\mathrm{D}$ and objective sleep phase ( $\mathrm{p}$ for

significance $\leq .004)$ : $r=.161, \mathrm{p}=.0020$

Note: EEG= Electroencephalogram, POMS=Profile of Mood States, VAS=visual analog scale, LFHC=low fat and high carbohydrate, HCLF=high carbohydrate and low fat, $\mathrm{SD}=$ standard deviation, $\mathrm{df}=$ degrees of freedom, MUFA=mono-unsaturated fatty acids, $\mathrm{PUFA}=$ poly-unsaturated fatty acids, $\mathrm{BMI}=$ body mass index, $\mathrm{EEG}=\mathrm{electroencephalograph}$, VAS=visual analog scale

Table C - Emotional Wellness: The effects of dietary intake on stress and anxiety in older adults.

\begin{tabular}{|c|c|c|c|c|c|}
\hline $\begin{array}{c}\text { Author \& } \\
\text { year }\end{array}$ & Objective & Design & Results & Statistics & $\begin{array}{l}\text { Confounders } \\
\text { adjusted for }\end{array}$ \\
\hline $\begin{array}{l}\text { Jacka et } \\
\text { al., } 2010\end{array}$ & $\begin{array}{l}\text { An } \\
\text { epidemiological } \\
\text { study from the } \\
\text { Geelong } \\
\text { Osteoporosis } \\
\text { Study examined } \\
\text { the relationship } \\
\text { between dietary } \\
\text { intake and } \\
\text { development of } \\
\text { various mental } \\
\text { disorders, } \\
\text { including } \\
\text { anxiety. }\end{array}$ & $\begin{array}{l}{ }^{*} 1,046 \text { women, mean age } 48-52 \\
\text { years old } \\
{ }^{*} \text { FFQ assessed dietary intake of } \\
\text { food } \\
{ }^{*} \text { Clinical interviews to assess } \\
\text { depression, dysthymia, and } \\
\text { anxiety } \\
{ }^{*} \text { GHQ-12 assessed psychological } \\
\text { symptoms } \\
{ }^{*} \text { Questionnaires assessed lifestyle } \\
\text { and socio-demographic info } \\
{ }^{*} \text { Diets were classified into } 1 \text { of } 3 \\
\text { patterns: Traditional, Western, or } \\
\text { Modern } \\
{ }^{*} \text { Diet quality score calculated }\end{array}$ & $\begin{array}{l}\text { *Western diet was associated with } \\
\text { more psychological symptoms } \\
{ }^{*} \text { Traditional diet was inversely } \\
\text { related to anxiety disorders in } \\
\text { unadjusted and fully adjusted } \\
\text { models } \\
{ }^{*} 35 \% \text { reduction in odds for anxiety } \\
\text { disorders for } 1 \text { SD increase in } \\
\text { traditional diet scores } \\
{ }^{*} \text { Modern diet was not associated } \\
\text { with anxiety } \\
{ }^{*} \text { A more healthful diet resulted in } \\
\text { fewer psychological symptoms }\end{array}$ & $\begin{array}{l}\text { OR for association diet pattern and anxiety } \\
\text { disorders -unadjusted }(95 \% \mathrm{CI}) \text { : Western: } \\
\text { 1.09(.88-1.36); Traditional: .81(.64-1.04); } \\
\text { Modern: .97(.77-1.23). OR for association diet } \\
\text { pattern and anxiety disorders - fully } \\
\text { adjusted (95\%CI, p<.05): Western: .76(.49- } \\
\text { 1.18); Traditional: .68(.47-.99); Modern: } \\
.93(.69-1.24)\end{array}$ & $\begin{array}{l}\text { Age, } \\
\text { socioeconomic } \\
\text { status, education, } \\
\text { activity, smoking, } \\
\text { alcohol use, } \\
\text { energy intake }\end{array}$ \\
\hline $\begin{array}{l}\text { Jacka et } \\
\text { al., } 2011\end{array}$ & $\begin{array}{l}\text { A nested cross- } \\
\text { sectional study of } \\
\text { older adults from } \\
\text { the Hordland } \\
\text { Health Study } \\
\text { examined diet } \\
\text { and common } \\
\text { mental disorders, }\end{array}$ & $\begin{array}{l}{ }^{*} 5,731 \text { adults, } 46+\text { years old } \\
{ }^{*} \text { FFQ assessed dietary intake } \\
{ }^{*} \text { Healthy food scores were } \\
\text { assigned to intake } \\
{ }^{*} \text { Subjects classified into } 1 \text { of } 3 \\
\text { eating patterns: Healthy, Western, } \\
\text { and Traditional Norwegian } \\
{ }^{*} \text { HADS-A assessed anxiety }\end{array}$ & $\begin{array}{l}{ }^{*} \text { Reduced anxiety risk of } 23 \% \text { for } \\
\text { every } 1 \text { SD increase in diet quality } \\
\text { score fully adjusted models } \\
{ }^{*} \text { No association between OR of } \\
\text { case-level anxiety and diet score in } \\
\text { men. } \\
{ }^{*} 19 \% \text { increased risk of anxiety } \\
\text { with each } 1 \text { SD increase in Healthy } \\
\text { eating pattern for men }\end{array}$ & $\begin{array}{l}\text { OR for association of diet quality score in } \\
\text { men }(95 \% \mathrm{CI}) \text { : unadjusted: } 1.04(.91-1.18), \\
\mathrm{p}=.57 \text {; fully adjusted: } 1.00(.85-1.17), \mathrm{p}=.98 \text {. } \\
\text { OR for association of diet quality score in } \\
\text { women }(95 \% \mathrm{CI}) \text { : unadjusted: } .86(.79-.94) \text {, } \\
\mathrm{p}=.001 \text {; fully adjusted: } .77(.68-.87), \mathrm{p}<.001 \text {. } \\
\text { OR for association of diet pattern and } \\
\text { anxiety disorders in men - unadjusted } \\
(95 \% \mathrm{CI}) \text { : Healthy: } 1.14(1.01-1.29), \mathrm{p}=.04 ;\end{array}$ & $\begin{array}{l}\text { Age group, } \\
\text { gender, total } \\
\text { energy intake, } \\
\text { smoking, alcohol, } \\
\text { education, } \\
\text { activity, WHR, } \\
\text { BP, self-reported } \\
\text { diabetes and }\end{array}$ \\
\hline
\end{tabular}


including

anxiety.

Beezhold A two-week

$\& \quad$ randomized

Johnston, controlled trial

2012 examined effects

of meat and fish

intake on mood.

${ }^{*}$ FFQ assessed fatty acid intake.

depression (DASS-D), anxiety

(DASS-A), stress (DASS-S),

tension-anxiety (POMS-T),

depression-dejection (POMS-D), anger-hostility (POMS-A), fatigueinertia (POMS-F), confusion-

bewilderment (POMS-C), vigoractivity (POMS-V) and mood

*Subjects were divided into three groups: OMN, FISH, and VEG

*See Jacka et al. 2010 for details
*Questionnaires assessed

* $16 \%$ reduced risk of anxiety with each 1SD increase in Healthy eating pattern for women * $23 \%$ reduced risk of anxiety for each 1SD increase in Traditional eating pattern for women *No association between

Norwegian diet and anxiety for men

* 95\% dietary adherence

*Baseline median POMS-C scores differed significantly between the OMN (9) and the VEG (3) groups *VEG subjects: EPA, DHA and AA reduced significantly and n6-to-n 3 ratio increased $60 \%$

*FISH subjects: EPA and DHA

rose $95-100 \%$

*OMN subjects: fatty acid intakes were unchanged

*VEG participants had much greater improvement in DASS-S,

POMS-C scores, and moderately better POMS-T and POMS-total scores compared to the other two groups

*Increasing fish consumption and avoiding meat did not improve mood
Western: 1.27(1.14-1.42), $\mathrm{p}<.001$; Traditional: .92(.81-1.05), $\mathrm{p}=.29$. OR for association of die pattern and anxiety disorders in men - fully adjusted (95\%CI): Healthy: 1.19(1.03-1.38), $\mathrm{p}=.02$; Western: $1.09(.87-1.36), \mathrm{p}=.52$; Traditional: .86(.70-1.05), $\mathrm{p}=.18$. OR for association of diet patterns and anxiety disorders in women - unadjusted $(95 \% \mathrm{CI})$ : Healthy: .84(.77-.93), $\mathrm{p}=.001$; Western: 1.29(1.17-1.43), $\mathrm{p}<.001$; Traditional: .88(.79.97), $\mathrm{p}=.007$. OR for association of diet pattern and anxiety disorders in women fully adjusted (95\%CI): Health: .87(.77-.98), $\mathrm{p}=.01$; Western: $1.18(.96-1.45), \mathrm{p}=.36$; Traditional: .77(.64-.92), $\mathrm{p}=.001$

DASS-S scores (median (IQR)) for baseline and $2 \mathrm{wk}$, respectively: $\mathrm{OMN}=20(28)$ and 14(16); FISH=18(18) and 8(13); VEG=21.5(25) and 8.5(14), $\mathrm{p}=.045$. POMS-C scores (median (IQR)) for baseline and $2 \mathrm{wk}$, respectively: $\mathrm{OMN}=3(5)$ and 4(5); FISH=5(5) and 4(5); $\mathrm{VEG}=9(8)$ and 3(6), $\mathrm{p}=.003$. POMS-T scores (median (IQR)) for baseline and $2 \mathrm{wk}$, respectively: $\mathrm{OMN}=6(4)$ and 5(5); $\mathrm{FISH}=7(5)$ and 7(4); VEG=8(8) and 4(4), p=.061. POMSTotal scores (median (IQR)) for baseline and $2 \mathrm{wk}$, respectively: $\mathrm{OMN}=8(26)$ and $3(22)$; FISH=18(18) and 8(13); VEG=21.5(25) and 5(23), $\mathrm{p}=.087$

Standardized z-score (95\%CI) for nutrient and GHQ-12 relationship: zinc= $-.16(-.29$ to - myocardial

infarction
${ }^{*}$ Only $70 \%, 26 \%$ and $8 \%$ of women meeting the RDI for zinc,
GHQ-12 adjusted for age 
the Geelong

Osteoporosis

Study analyzed

magnesium,

folate, and zinc

intake as each

pertained to

GHQ-12 scores,

depression and

anxiety

disorders.

Jacka

al., 2012b examination of

the Geelong

Osteoporosis

Study analyzed

red meat intake

and the

association

between GHQ-12

scores,

depression and

anxiety

disorders.

$\begin{array}{ll}\text { Jacka et } & \text { Further } \\ \text { al., 2013 } & \text { examination of } \\ & \text { the Geelong } \\ & \text { Osteoporosis } \\ & \text { Study analyzed } \\ & \text { fish and PUFA } \\ & \text { intake and the } \\ & \text { association with }\end{array}$

magnesium and folate,

respectively

*Zinc and magnesium intake were significantly inversely associated with GHQ-12 scores

*All 3 micronutrients were negatively associated with depression

*No association between any of the 3 nutrients and anxiety

*See Jacka et al., 2010 for details *Based on Australian

recommendations (3-4 servings/wk), red meat intake was categorized as low $(<28 \mathrm{~g})$,

recommended $(28-57 \mathrm{~g})$, and high $(>57 \mathrm{~g})$

*The Traditional dietary pattern

was used as an indicator of an

overall healthful diet

*935 women, mean age 50 years old

*See Jacka et al., 2010 for details *FFQ assessed PUFA and fish intake

*Median intake of meat was $39.3 \mathrm{~g} / \mathrm{d}$ (recommended)

*Women consuming lower than the recommended intake had increased risk of anxiety compared to those in the

*Higher red meat intake was not associated with anxiety

*Those consuming lower than recommended amounts of red meat had higher GHQ-12 scores *High red meat intake was not associated with GHQ-12 scores

*No differences between vegetarians in relation to menta health

*n-6 and n-3 PUFA intake met adequate intakes. N-3 intakes also met adequate intakes, but ${ }^{*} \mathrm{~N}-6$ and n-3 did not meet suggested intake for optimal
$.04), \mathrm{p}=.01 ;$ magnesium $=-.14$ (-.26 to -.03$)$, $\mathrm{p}=.02$; folate $=-.09(-.18-.01), \mathrm{p}=.06$.

OR $(95 \% \mathrm{CI})$ for nutrient and depression: zinc $=.52(.31-.88), \mathrm{p}=.01$; magnesium $=.60(.37$ $.96), \mathrm{p}=.03$; folate $=.66(.45-.97), \mathrm{p}=.03$. OR (95\% CI) for nutrient and anxiety: zinc $=.76(.48-1.19), \mathrm{p}=.23$; magnesium $=.81(.54$ 1.23), $\mathrm{p}=.32$; folate $=.81(.58-1.13), \mathrm{p}=.21$ recommended range $(\mathrm{n}=18)$ health for Australian women $51 \%$ of subjects ate fish at least once per week

OR $(95 \% \mathrm{CI})$ for anxiety based on red meat intake, adjusted for age: low intake:

3.16).

OR $(95 \% \mathrm{CI})$ for anxiety based on red meat intake, adjusted for Traditional diet pattern score: low intake: 1.82(1.01-3.27), $\mathrm{p}<.05$; high intake: $1.85(.99-3.48)$
OR( $95 \% \mathrm{CI})$ of DHA and major depressive disorder/dysthymia by tertile:

1st=1(reference), 2nd=.31(.12-.79)

$3 \mathrm{rd}=1.44(.73-2.83)$. OR(95\%CI) of DHA and anxiety disorders by tertile: $1 \mathrm{st}=1$ (reference), 2nd $=.78(.43-1.42)$, 3rd=.49(.24-.98)

Beta-coefficients $(95 \% \mathrm{CI})$ of fish intake and

GHQ-12 scores, fully adjusted: Fish(g/d) in smokers= $-.14(-.37-.03), \mathrm{p}=.19$; fish $(\mathrm{g} / \mathrm{d})$ in

socioeconomic status, activity, education,

alcohol, smoking, and energy

intake.

Depression and

anxiety diagnosis adjusted for energy intake only

Age and

Traditional diet

pattern

OR adjusted for energy intake and diet quality score. Betacoefficients adjusted for age BMI,

socioeconomic status, activity 
depression and

anxiety.

Ford et al., An observational 2013 study of Seventh Day Adventists

from the

Adventist Health

Study-2 cohort examined typical

Mediterranean

versus Western

foods and their

association with

negative and

positive affect.
*7.1\% of women were diagnosed with anxiety

* $5.5 \%$ of women were diagnosed with depression

*Women with anxiety tended to

be younger than those without

${ }^{*}$ A linear relationship between

DHA and reduced anxiety existed

*A non-linear relationship

between DHA and reduced

depression existed

*Stronger relationship between

fish and reduced psychological

symptoms in smokers compared

to non-smokers

*9,255 adults, 35+years old (mean age 62.9)

* FFQ assessed dietary intake of food

*Food items were categorized into Mediterranean (non-starchy fresh produce, certain dairy products, fish, nuts, olive oil, and legumes except soy) or Western (red and processed meats, sweets/desserts, soda, fast food)

*PANAS assessed affect

* Mediterranean food consumption associated with increased positive affect

${ }^{*}$ Western food consumption

associated with increased negative affect

* Red meat and fast food frequency were associated with negative affect in women only

*The overall association between negative affect and food intakes was stronger in women than in non-smokers $=-.03(-.12-.06), \mathrm{p}=.53$; Fish

$\geq 1 \mathrm{x} /$ wk in smokers $=-.49(-.91$ to -.07$), \mathrm{p}=.02$;

Fish $\geq 1 \mathrm{x} /$ wk in nonsmokers $=-.10(-.25-.05)$, $\mathrm{p}=.17$

level, alcohol, energy intake, and diet quality score

Regression of positive and negative affect men

${ }^{*}$ Men consumed more red and processed meats, nuts, sweets, soda and fast food

*Women consumed more vegetables

*Increased intake of nuts was positively associated with higher positive and lower negative affect respectively, on energy-adjusted food intake in women (Beta $(95 \% \mathrm{CI})$ ): fresh

vegetables=.139(.110-.167, $\mathrm{p}<.001$ and $-.091(-$ .121 to -.061$), \mathrm{p}<.001$; fresh fruit $=.072(.048$ $.096), \mathrm{p}<.001$ and $-.040(-.065$ to -.015$), \mathrm{p}=.002$; dairy $=-.022(-.039$ to -.005$), \mathrm{p}=.013$ and $.016(-$ $.002-.034), \mathrm{p}=.085$; olive oil=.082(.032-.132),

$\mathrm{p}=.001$ and $-.070(-.122$ to -.018$), \mathrm{p}=.008$; nuts $=.045(.009-.081), \mathrm{p}=.016$ and $-.101(-.138$ to $-.065), \mathrm{p}<.001$; fish $=.013(-.024-.051), \mathrm{p}=.487$ and $.029(-.011-.068), \mathrm{p}=.152$;

legumes $=.059(.030-.088), \mathrm{p}<.001$ and $-.033(-$ .062 to -.004$), \mathrm{p}=.026$; red meats $=-.072(-.117$ to -.026$), \mathrm{p}=.002$ and $.085(.038-.133), \mathrm{p}<.001$; processed meats $=-.176(-.316$ to -.036$), \mathrm{p}=.014$ and $.197(.049-.345), \mathrm{p}=.009$; sweets and desserts $=-.073(-.099$ to -.047$), \mathrm{p}<.001$ and $.073(.046-.100), \mathrm{p}<.001 ;$ soda $=-.027(-.042$ to $.012), \mathrm{p}<.001$ and $.026(.010-.041), \mathrm{p}=.001$; fast food frequency $=-.055(-.075$ to -.035$), \mathrm{p}<.001$ and .079(.058-.100), $\mathrm{p}<.001$. Regression of
Education, activity level, sleep patterns, age, gender ethnicity, BMI, alcohol, total energy intake, and time between the two questionnaires

(FFQ and PANAS) 


\section{Hodge et Cross-sectional al., 2013 \\ study of}

participants from

the Melbourne

Collaborative

Cohort Study,

primarily

examining the

effects of the

Mediterranean

diet (traditional

or modified) and

a more

traditional

Australian diet positive and negative affect, respectively, on energy-adjusted food intake in men (Beta (95\%CI)): fresh vegetables=.093(.053-.133),

$\mathrm{p}<.001$ and $-.046(-.082$ to -.010$), \mathrm{p}=.013$; fresh fruit $=.053(.021-.085), \mathrm{p}=.001$ and $-.021(-.051-$ $.009), \mathrm{p}=.167$; dairy=.008(-.015-.032), $\mathrm{p}=.489$ and $-.011(-.032-.010), \mathrm{p}=.323$; olive oil $=.046(-$ $.025-.117), \mathrm{p}=.207$ and $.017(-.047-.082), \mathrm{p}=.594$; nuts $=.083(.036-.130), \mathrm{p}=.001$ and $-.060(-.102$ to -.017), $\mathrm{p}=.006$; fish $=.067(.017-.117), \mathrm{p}=.008$ and -.019(-.065-.027), $\mathrm{p}=.413$; legumes $=.054(.015-.093), \mathrm{p}=.007$ and $-.015(-$ $.051-.020), \mathrm{p}=.391$; red meat $=-.027(-.083-.030)$, $\mathrm{p}=.359$ and $-.026(-.078-.026), \mathrm{p}=.325$; processed meats $=-.083(-.240-.074), \mathrm{p}=.298$ and .032(-.111-.174), $\mathrm{p}=.665$; sweets and desserts $=-.054(-.087$ to -.020$), p=.002$ and $.032(.002-.062), \mathrm{p}=.035 ;$ soda $=-.046(-.007$ to $.010), \mathrm{p}=.008$ and $.001(-.017-.019), \mathrm{p}=.920$; fast food frequency $=-.034(-.060$ to -.008$), \mathrm{p}=.011$ and $.007(-.016-.031), \mathrm{p}=.556$

Highest quintile of Mediterranean-style: K10 score $<20=10.6 \%,>20=11.1 \%, p=.736$

${ }^{*} \mathrm{FFQ}$ assessed dietary intake, with higher total energy intake were

MDS score calculated accordingly *Questionnaires assessed lifestyle, health history and socio-

demographic info associated with higher K10 scores *The Mediterranean pattern was associated with lower K10 scores *MDS was inversely associated *Subjects with clinical diagnosis of with stress Australian style diet: K10 score $<20=29.3 \%$, $\geq 20=33.1 \%, p=.007$. MDS and psychological distress based on $\mathrm{K} 10$ scores $(\mathrm{OR}(95 \% \mathrm{CI})$ ): Energy Intake: 1.05 (1.02-1.07),MDS score 03: 1.00 (reference); MDS score 4-6: .94 (.771.13); MDS score 7-9: .72 (.54-.95)

K10 exam assessed distress (low score indicates low stress and high score indicates highly stressed

Physical activity level, education smoking status, history of arthritis, asthma, kidney stones or gallstones,

SocioEconomic Indexes for Areas, and dietary energy 
on psychological

distress.

Roohafza A cross-sectional

et al., 2013 study of

participants from

the Isfahan

Healthy Heart

Program

examined stress

levels and food

consumption.
*9,549 adults, 18+ years old ${ }^{*}$ FFQ assessed dietary intake *GDI score assigned based on FFQ (lower GDI indicates better diet)

*Lifestyle, health history and socio-demographic information collected

*Body weight, height, BMI, and blood pressure were measured ${ }^{*}$ GHQ-12 assessed stress (4+ points indicates high stress)
*Low stress subjects consumed more unsaturated oils, fresh

produce, grains, meat and dairy

${ }^{*}$ High stress subjects consumed more saturated oils

*Overall lower GDI scores in in

low stress group

*Positive association between

stress levels and GDI and

saturated oil

*Inverse association between

stress and both $\mathrm{f \& v}$ and

stress and both $\mathrm{f} \& \mathrm{v}$
unsaturated oils

Note: *FFQ=Food frequency questionnaire, HADS-A=Hospital Anxiety and Depression Scale, Anxiety, WHR=Waist hip ratio, BP=blood pressure, OR=Odds ratio, $\mathrm{CI}=$ confidence interval, GHQ= General Health Questionnaire, SD=Standard deviation, DASS-D=Depression Anxiety Stress Scale Depression, DASS-A=Depression Anxiety Stress Scale Anxiety, DASS-S=Depression Anxiety Stress Scale Stress, POMS=Profile of Mood States, POMS-T=Profile of Mood States Tension-anxiety, POMS-D=Profile of Mood States Depression, POMS-A=Profile of Mood States Anger-hostility, POMS-F=Profile of Mood States Fatigue-inertia, POMS-C=Profile of Mood States Confusion-bewilderment, POMS-V=Profile of Mood States Vigor-activity, DHA=docosahexaenoic acid, EPA=eicosapentaenoic acid, AA=Amino acids, PUFA=Polyunsaturated fatty acids, PANAS= Positive and Negative Affect Schedule, MDS=Mediterranean Diet Score, K10=Kessler Psychological Distress Scale, GDI=Global Dietary Intake

Table D - Physical Wellness: The effects of dietary intake on mortality in older adults.

\begin{tabular}{|c|c|c|c|c|c|}
\hline $\begin{array}{c}\text { Author \& } \\
\text { year }\end{array}$ & Objective & Design & Results & Statistics & $\begin{array}{l}\text { Confounders } \\
\text { adjusted for }\end{array}$ \\
\hline $\begin{array}{l}\text { Osler et } \\
\text { al., } 1997\end{array}$ & $\begin{array}{l}\text { A prospective } \\
\text { analysis of } 202 \\
\text { elderly } \\
\text { Europeans from } \\
\text { the Euronut } \\
\text { SENECA study } \\
\text { examined } \\
\text { Mediterranean } \\
\text { Diet Score and } \\
\text { the association } \\
\text { with survival. }\end{array}$ & $\begin{array}{l}{ }^{*} 202 \text { adults, mean age 72-73yo } \\
{ }^{*} 6 y \text { follow-up } \\
{ }^{*} \text { FFQ assessed dietary intake } \\
\text { * Fasting blood samples assessed } \\
\text { total cholesterol, HDL, carotene } \\
\text { and vit E were taken } \\
\text { *Lifestyle questions answered } \\
\text { *Diet score was based on } 7 \\
\text { components, each assigned } 1 \\
\text { point, (high score=good diet): high } \\
\text { mono- to saturated fat ratio, }\end{array}$ & $\begin{array}{l}{ }^{*} \text { Cereal intake was positively } \\
\text { associated with mortality } \\
{ }^{*} \text { No significant association } \\
\text { between all other dietary } \\
\text { components and mortality } \\
{ }^{*} \text { The 7-point diet score was } \\
\text { inversely associated with } \\
\text { mortality } \\
{ }^{*} \text { Higher plasma carotene levels in } \\
\text { subjects with higher diet scores } \\
\text { (>3 points) }\end{array}$ & $\begin{array}{l}\text { Mean(SD) intake of dietary components for } \\
\text { deceased and surviving, respectively and } \\
\text { Rate Ratio per 20g change }(95 \% \mathrm{CI}) \text { : } \\
\text { vegetables=291(148) and } 290(117) \text {, } \\
\mathrm{RR}=.99(.95-1.04) \text {; fruits=143(122) and } \\
136(104), \mathrm{RR}=1.02(.97-1.08) \text {; dairy=312(242) } \\
\text { and 291(221), RR=1.00(.99-1.01); } \\
\text { cereals=213(121) and } 191(74), \mathrm{RR}=1.10(1.03- \\
1.17) ; \text { meat=116(49) and } 116(44), \mathrm{RR}=.99(.86- \\
1.13) \text {; ethanol=8(10) and } 11(17), \mathrm{RR}=.81(.63- \\
1.05) ; \text { mono:saturated fat ratio=.9(.2) and }\end{array}$ & $\begin{array}{l}\text { Baseline age, } \\
\text { gender, smoking, } \\
\text { and individual } \\
\text { dietary variables }\end{array}$ \\
\hline
\end{tabular}


moderate ethanol consumption, high consumption of each - cereal, fruit, and vegetable and legumes, low consumption of meat and of milk/dairy products.
${ }^{*}$ Negative association with serum cholesterol and plasma carotene and mortality
Huijbregt

1997
A prospective analysis of men from Finland, Italy and the Netherlands examined dietary recommendation $\mathrm{s}$ from the $\mathrm{WHO}$ and the association with all-cause mortality. study examined whole vs. refined grain intake and
*3,045 men, mean baseline age 5860 yo

*20y follow-up

*Diet history and food records assessed dietary intake

*Diets scored based on adherence to the WHO guidelines for prevention of chronic disease, each component being assigned 1 point (high score=high adherence and good diet), including: saturated fat, PUFA, protein complex carbohydrates, fiber, $\mathrm{f \& v}$, pulses/nuts/seeds, mono- and disaccharides, and cholesterol *Subjects divided into low, medium and high adherence

*Death certificates and/or medical and hospital records confirmed death

*34,333 women, mean baseline age $61.5 \mathrm{yo}$

*9y follow-up

${ }^{*} \mathrm{FFQ}$ assessed dietary intake
1.0(.3), $\mathrm{RR}=.24(.07-1.13)$; total energy=8.6(.3) and $9.1(.4), \mathrm{RR}=\mathrm{NA}$.

Rate ratio (95\%CI) of diet score (1 unit) as predictor of survival time $=.79(.64-.98)$. Mean (SD) serum levels and rate ratio (95\%CI) with each variable as a predictor of survival time: total serum cholesterol: low diet score $=6.4(1.3)$, high diet score $=6.7(1.2)$, $\mathrm{p}=.06$, deceased $=6.1(1.2)$, survivors $=6.7(1.2)$, $\mathrm{RR}=.96(.94-.99)$; carotene: low diet score $=.5(.4)$, high diet score $=.7(.5), \mathrm{p}=.00$, deceased $=.5(.7)$, surviving $=.7(.5), \mathrm{RR}=.48(.34$ .70)

RR $(95 \% \mathrm{CI})$ of all-cause mortality associated with $\mathrm{WHO}$ diet adherence in the pooled population, fully adjusted model:

Low $=1$ (reference), medium=.99(.87-1.11), high $=.87(.77-.98), \mathrm{p}$ for trend $=.03$. RR (95\%CI) of all-cause mortality associated with WHO diet adherence in Finland, fully adjusted model: Low $=1$, medium $=.97$ (.831.12), high=.90(.73-1.10), $\mathrm{p}$ for trend=.31. RR (95\%CI) of all-cause mortality associated

with WHO diet adherence in the

Netherlands, fully adjusted model: Low $=1$, medium $=.91(.72-1.16)$, high $=.75(.53-1.05), \mathrm{p}$ for trend $=.09$. RR $(95 \% \mathrm{CI})$ of all-cause mortality associated with $\mathrm{WHO}$ diet adherence in Italy, fully adjusted model: Low $=1$, medium $=1.04(.86-1.26)$, high $=.89(.72$ 1.09), $\mathrm{p}$ for trend $=.23$

HRR $(95 \% \mathrm{CI})$ of whole grains and cause of death by quintile, fully adjusted $(\mathrm{Q} 1$ is reference): Total mortality: $\mathrm{Q} 2=.95(.85-1.06)$ $\mathrm{Q} 3=.87(.78-.98), \mathrm{Q} 4=.81(.72-.91), \mathrm{Q} 5=.86(.76-$
Age, smoking alcohol

Age, energy intake, education, marital status, high blood 
association with

all-cause and cause-specific mortality.
Osler et al., 2001
A prospective analysis of Danish adults from the MONICA surveys

examined predefined healthy food index and a posteriori diets, and association with mortality.
*Questionnaires assessed lifestyle and socio-demographic info ${ }^{*}$ Grain intakes were divided into quintiles ranging from 0 to 3-4 servings per day
*Dark breads and breakfast cereals contributed the most to whole grains

*Sweets and white bread contributed the most to refined grain intake

*Daily consumption of whole grains was associated with higher socioeconomic status, thinness, lower presence of cancer, $\mathrm{CHD}$ HTN and DM at baseline, and more positive health behaviors

*Higher level of whole grain consumption was associated with fewer refined grains, red meats, and total and saturated fat intakes *Whole grain intake negatively associated with overall risk of death

${ }^{*}$ Refined grain intake positively associated with death *Consumption of at least 1 serving/d of whole grains significantly reduced risk of death

*5,871 adults $(\mathrm{m}=2,994, \mathrm{f}=2,877)$, age 30-70yo

*15y median follow-up

${ }^{*} \mathrm{FFQ}$ assessed dietary intake

${ }^{*} \mathrm{Ht}$ and wt measured and BMI calculated

*Questionnaires assessed socioeconomic and lifestyle factors

* Characteristics of healthy food index were assigned 1 point each for the following: not consuming lard, butter or margarine daily; consuming raw or boiled

*4-point healthy food index scoring was not associated with mortality in fully adjusted models *Men scoring only 1 point (least healthful) appeared to have the lowest risk of mortality

*Prudent dietary pattern was inversely associated with both mortality and cardiovascular disease in women

*Women in the highest quartile had $54 \%$ lower mortality
.97), $\mathrm{p}$ for trend=.005; All cancer: $\mathrm{Q} 2=.85(.72-$ 1.0), Q3=.84(.71-.99), Q4=.83(.70-.99), $\mathrm{Q} 5=.89(.75-1.05), \mathrm{p}$ for trend $=.34$; All cardiovascular disease: $\mathrm{Q} 2=1.01(.84-1.21)$, $\mathrm{Q} 3=.85(.70-1.04), \mathrm{Q} 4=.78(.63-.97), \mathrm{Q} 5=.82(.66-$ 1.01): All non-cancer/non-CVD: $\mathrm{Q} 2=1.07(.85$ 1.34), Q3=.96(.75-1.23), Q4=.81(.62-1.05), $\mathrm{Q} 5=.86(.67-1.12), \mathrm{p}$ for trend $=.09$. HRR ( $95 \% \mathrm{CI})$ of refined grains and cause of death by quintile, fully adjusted (Q1 is reference):

Total mortality: Q2=1.07(.95-1.21), $\mathrm{Q} 3=1.04(.92-1.18), \mathrm{Q} 4=1.09(.97-1.24)$ $\mathrm{Q} 5=1.16(1.01-1.33), \mathrm{p}$ for trend $=.04$ : Nonmalignant respiratory disease: $\mathrm{Q} 2=.72(.44-1.17), \mathrm{Q} 3=.86(.53-1.39)$, $\mathrm{Q} 4=1.21(.78-1.88), \mathrm{Q} 5=1.28(.80-2.03), \mathrm{p}$ for trend $=.05$

pressure, $\mathrm{DM}$

heart disease,

cancer, BMI,

WHR, age at first childbirth,

activity, smoking, alcohol, supplement use, ERT, total fat, saturated fat, $\mathrm{f} \& \mathrm{v}$ intake, red meat intake, and

fish/seafood intake

HRRE (95\%CI) for healthy food index: men fully adjusted=.95(.86-1.05); women fully adjusted=.96(.85-1.09). HRRE (95\%CI) for prudent diet: men fully adjusted $=.84(.75-.93) ; \quad$ and $\mathrm{BMI}^{\wedge} 2$ women fully adjusted=.74(.64-.85). HRRE for Western diet (95\%CI): men fully adjusted=1.01(.90-1.12); women fully adjusted $=.91(.80-1.03)$. HRRE based on categories $(95 \% \mathrm{CI})$ Healthy food index $3+4$ point: men fully adjusted=.82(.58-1.14); women fully adjusted $=.82(.54-1.25)$. HRRE based on categories (95\%CI) Prudent diet
Smoking, activity, alcohol, 


\begin{tabular}{|c|c|c|c|c|c|}
\hline & & $\begin{array}{l}\text { vegetables at least } 1 \mathrm{x} / \mathrm{d} \text {; } \\
\text { consuming coarse white or coarse } \\
\text { rye bread at least } 1 \mathrm{x} / \mathrm{d} \text {; consuming } \\
\text { fruit at least } 1 \mathrm{x} / \mathrm{d} \\
{ }^{*} \text { Dietary intake separated into } 2 \\
\text { different patterns: prudent } \\
\text { (frequent intake of whole-meal } \\
\text { bread, pasta, rice, oatmeal, f\&v, } \\
\text { and fish) and Western (frequent } \\
\text { intake of sausages, meat, potatoes, } \\
\text { butter and white bread) }\end{array}$ & $\begin{array}{l}\text { compared to the lowest (reference) } \\
\text { quartile. } \\
{ }^{*} \text { Men in the highest quartile for } \\
\text { prudent diet had a } 30 \% \text { reduced } \\
\text { mortality risk compared to the } \\
\text { lowest quartile } \\
{ }^{*} \text { Typical Danish diet } \\
\text { (characterized by the Western } \\
\text { pattern) was not associated with } \\
\text { mortality }\end{array}$ & $\begin{array}{l}\text { 4th quartile: men fully adjusted }=.70(.49-1.0) \text {; } \\
\text { women fully adjusted }=.46(.30-.72)\end{array}$ & \\
\hline $\begin{array}{l}\text { Steffen et } \\
\text { al., } 2003\end{array}$ & $\begin{array}{l}\text { A prospective } \\
\text { analysis from the } \\
\text { ARIC Study } \\
\text { examined whole } \\
\text { and refined grain } \\
\text { and } \& \& v \\
\text { consumption and } \\
\text { the associations } \\
\text { with all-cause } \\
\text { mortality and } \\
\text { CAD risk. }\end{array}$ & $\begin{array}{l}{ }^{*} 11,940 \text { adults, age } 45-64 \text { yo } \\
{ }^{*} 11 \text { y follow up } \\
{ }^{*} \text { FFQ assessed dietary intake } \\
{ }^{*} \text { Ischemic stroke, CAD and all- } \\
\text { cause mortality assessed via } \\
\text { medical records, hospital records, } \\
\text { and relatives of subjects } \\
{ }^{*} \text { Refined and whole grain and f\&v } \\
\text { intakes were divided into quintiles }\end{array}$ & $\begin{array}{l}{ }^{*} \text { Median intakes of whole and } \\
\text { refined grains were } 1 \text { serving/d } \\
\text { and } 2 \text { servings/d, respectively } \\
{ }^{*} \text { Those in the highest quintile for } \\
\text { whole-grain consumption had } \\
23 \% \text { lower risk of all-cause } \\
\text { mortality than those in the lowest } \\
\text { quintile } \\
\text { *Fruit and vegetable consumption } \\
\text { was inversely related to total } \\
\text { mortality in fully adjusted models } \\
\text { *Intake of whole-grains and f\&v } \\
\text { were inversely associated with } \\
\text { total mortality } \\
\text { *Whole-grains were inversely } \\
\text { associated with CAD } \\
\text { *Incidence of ischemic stroke was } \\
\text { not affected by intake of either } \\
\text { grain type or f\&v }\end{array}$ & 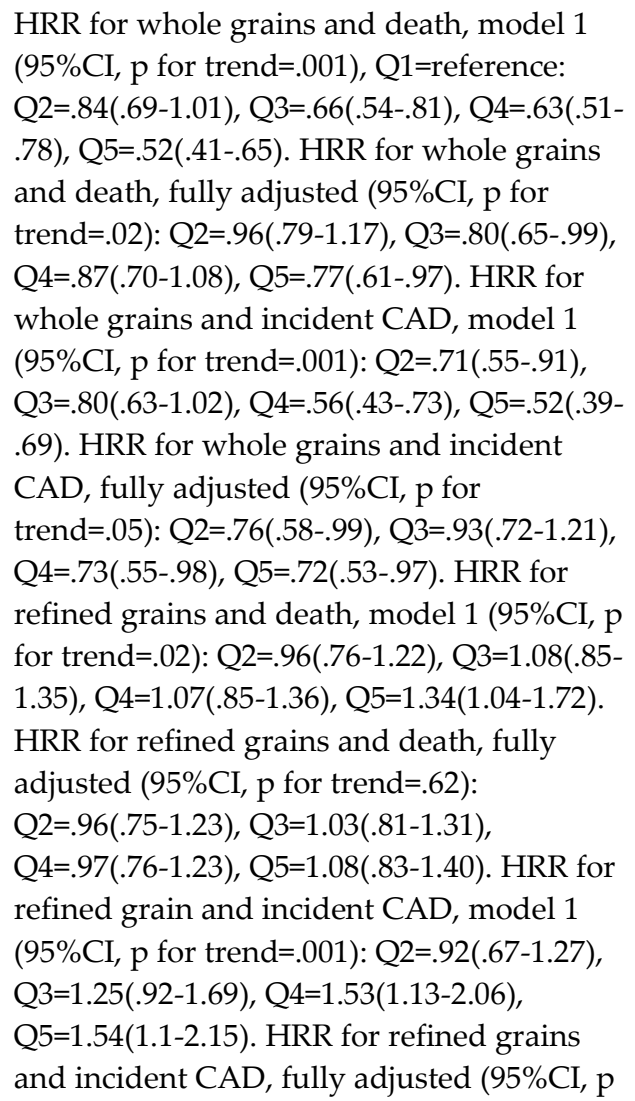 & $\begin{array}{l}\text { Model 1: age at } \\
\text { baseline, race, } \\
\text { gender, and } \\
\text { energy intake. } \\
\text { Fully adjusted: } \\
\text { model 1 } \\
\text { covariates plus } \\
\text { education, } \\
\text { smoking, pack- } \\
\text { years of smoking, } \\
\text { activity level, } \\
\text { alcohol, hormone } \\
\text { replacement } \\
\text { therapy in } \\
\text { women, BMI, } \\
\text { WHR, SBP and } \\
\text { use of anti-HTN } \\
\text { meds (further } \\
\text { adjusted for HDL } \\
\text { and LDL in } \\
\text { incident CAD } \\
\text { only) }\end{array}$ \\
\hline
\end{tabular}


Genkinge A prospective $\mathrm{r}$ et al., analysis from the 2004 Odyssey Cohort
*6,151 adults ( $\mathrm{m}=2276, \mathrm{f}=3875)$, mean age range 52.2-59.0 examined fruit, vegetable and antioxidant intake and the association with all-cause,

cardiovascular disease, and cancer-related deaths.
${ }^{*}$ FFQ assessed dietary intake

${ }^{*}$ Baseline questionnaires included demographics and medical history ${ }^{*} \mathrm{Ht}$, wt, and plasma cholesterol measured at baseline

*Vital status ascertained based on Maryland state death certificates *Subjects divided into quintiles based on intake

*Dietary constituents were further assessed by comparing the top 4 quartiles with the bottom quartile *Further analysis was completed to determine if adherence to the 5A-Day $f \& v$ guidelines was protective against all-cause, cancer and CVD deaths
*Median f\&v intake was 2.3 servings/d

*Subjects in the top fifth for each of $\mathrm{f} \& \mathrm{v}$, cruciferous vegetables, and energy-adjusted beta-carotene had lower risk of all-cause mortality than those in the respective lowest quartiles

* Risk of death from cancer decreased as total $\mathrm{f} \& \mathrm{v}$ intake increased

* Risk of death from CVD decreased slightly for those in the top quartile of both total $\mathrm{f} \& \mathrm{v}$ and cruciferous vegetable intakes, compared with the lowest quartiles

*When comparing Q1 with Q2-Q5, a protective effect existed in allcause mortality from intake of cruciferous vegetables, for cancer from intake total $\mathrm{f} \& \mathrm{v}$ and cruciferous vegetables ${ }^{*} 9 \%$ of subjects reported adherence to the 5-A-Day guidelines for trend=11): Q2=.91(.65-1.27), Q3=1.14(.83-

1.56), $\mathrm{Q} 4=1.28(.93-1.75), \mathrm{Q} 5=1.17(.82-1.66)$.

HRR for $\mathrm{f} \& \mathrm{v}$ intake and death, model 1

(95\%CI, p for trend=.001): Q2=.97(.80-1.19), $\mathrm{Q} 3=.76(.62-.94), \mathrm{Q} 4=.64(.51-.80), \mathrm{Q} 5=.53(.42-$

.68). HRR for f\&v intake and death, fully adjusted $(95 \% \mathrm{CI}, \mathrm{p}$ for trend $=.02)$ : $\mathrm{Q} 2=1.08(.88-1.33), \mathrm{Q} 3=.94(.75-1.17)$, $\mathrm{Q} 4=.87(.68-1.10), \mathrm{Q} 5=.78(.61-1.01)$

HR $(95 \% \mathrm{CI})$ for quartile 5 intake and allcause mortality (Q1=reference): total $\mathrm{f} \& \mathrm{v}=.63(.51-.78), \mathrm{p}$ for trend $=.0004$; cruciferous vegetables $=.78(.64-.96), \mathrm{p}$ for trend $=.13)$; . beta-carotene $=.81(.66-1.00), \mathrm{p}$ for trend $=.19$. HR $(95 \% \mathrm{CI})$ for quartile 5 intake and cancer mortality: total $\mathrm{f} \& \mathrm{v}=.65(.45-.93)$, p for trend $=.08$. HR $(95 \% \mathrm{CI})$ for quartile 5 intake and CVD mortality: total $\mathrm{f} \& \mathrm{v}=.76(.54-$ 1.06), $\mathrm{p}$ for trend $=.15$; cruciferous vegetables $=.89(.64-1.25)$, $\mathrm{p}$ for trend $=.51$. HR (95\% CI) of dietary constituents and death when comparing Q1 with Q2-5: cruciferous vegetables and all-cause mortality $=.32(.13$ $.80)$; $\mathrm{f} \& \mathrm{v}$ and cancer=.85(.73-.99); cruciferous vegetables and cancer $=.25(.05-1.14)$.

$\mathrm{HR}(95 \% \mathrm{CI})$ of adherence to 5-a-day guidelines and death: all-cause mortality $=.80(.64-1.0)$; cancer $=.77(.51-1.15)$
F\&V and cruciferous vegetables adjusted for age smoking, BMI cholesterol, and energy.

Antioxidants further adjusted for energy intake 


\section{A prospective} analysis of US adults examined various dietary patterns with allcause mortality.
${ }^{*} 10,084$ adults $(\mathrm{m}=4146, \mathrm{f}=5938)$, mean age $60 \mathrm{yo}$

*5.9y median follow-up

*FFQ assessed dietary intake and dietary behaviors

*National Death Index was used

to assess mortality and/or disease state at follow up

*Dietary patterns assessed

included the Recommended Foods and Behaviors Score (RFBS,

included following guidelines for recommended intake such as $\mathrm{f} \& \mathrm{v}$, whole grains, low/non fat dairy, etc....), factor-analyzed patterns (1st factor was fruit-veg-whole grain (FVG), 2nd factor was ethnic pattern including foods such as beans/tortillas, 3rd factor was lowfat including skim milk and lowfat behaviors) and clusteranalyzed patterns (including 1 . less likely to eat whole grain, low/non fat dairy, or remove fat from meat and poultry, 2. less likely to mention most fruits and vegetables, 3 . less likely to mention high-fiber cereal and
*Risk was lower for all-cause and cancer deaths with adherence to the 5-A-Day guidelines

* CVD death was not associated with adherence to the 5-a-day guideline

*Beta-carotene was associated with lower risk of all-cause mortality

${ }^{*}$ High RFBS and FVG scores were related to higher energy,

micronutrient and fiber intakes and lower saturated and total fat

* Mean total and saturated fats were lower and micronutrients higher in the 4th cluster * Men displayed an inverse trend for risk of all-cause mortality associated with RFBS and FVG scores in fully-adjusted models * Lower mortality risk in the 4 th cluster compared to the 1 st (reference) in fully adjusted models

RR of all-cause mortality associated with dietary patterns in men, fully adjusted, $(95 \% \mathrm{CI})$, level 1 for all categories = reference: race/ethnicity, RFBS Q2=.88(.72-1.08), Q3=.84(.68-1.03), $\mathrm{Q} 4=.72(.56-.92), \mathrm{p}$ for trend $=.001 ; \mathrm{FVG}$ $\mathrm{Q} 2=.92(.74-1.13)$, FVG Q3=.84(.68-1.06), FVG $\mathrm{Q} 4=.74(.57-.95), \mathrm{p}$ for trend $=.002$; Cluster $2=.94(.76-1.16)$, Cluster $3=.87(.71-1.07)$, Cluster 4=.82(.66-1.01). RR of all-cause mortality associated with dietary patterns in women, fully adjusted, (95\%CI): RFBS $\mathrm{Q} 2=.95(.76-1.18), \mathrm{Q} 3=.80(.64-1.02)$ $\mathrm{Q} 4=.80(.61-1.04)$, $\mathrm{p}$ for trend $=.04 ; \mathrm{FVG}$ $\mathrm{Q} 2=.89(.72-1.08)$, FVG Q3=.81(.64-1.02), FVG $\mathrm{Q} 4=.87(.67-1.11)$, $\mathrm{p}$ for trend $=.09$; Cluster $2=.93(.75-1.16)$, Cluster $3=.93(.74-1.17)$, Cluster $4=.88(.72-1.09)$
Year of survey education, BMI, smoking, supplement use, alcohol use, total energy intake 
most fruits, and 4. highest

proportion reporting weekly use of most items related to RFBS)

*RFBS and FVG factor diets were analyzed based on quartiles (RFBS Q1 $=0-8$ pts, Q2=9-11pts, Q3=1214 pts, Q4 $\geq 15$ pts)

Knoops et A prospective al., 2006 analysis from the HALE project examined association between three different dietary scores and allcause mortality.
*3,093 adults $(\mathrm{m}=2044, \mathrm{f}=1049)$, age 70-90yo

*10y follow-up

*Food records and oral interview assessed dietary intake

*Wt and ht measured

*BMI calculated

${ }^{*}$ Questionnaires assessed lifestyle

*Subjects divided into Northern and Southern European countries * A modified MDS ranging from 0 (poor quality diet) to 9 (high quality) assessed mono- to saturated-fat ratio,

legumes/nuts/seeds, cereals, fruit, vegetables and potatoes, alcohol, meat and poultry, dairy, and fish. * The modified MDI measured Mediterranean style diet (bread, cereal, legumes, potatoes, fruit and vegetables, fish

monounsaturated fats, and red wine) and non-Mediterranean (milk, cheese, eggs, saturated fats, sweets, meat and sugar)

*The HDI measured adherence to guidelines for prevention of chronic disease as defined by the $\mathrm{WHO}$, with score ranges from 0-9
*All three diet scores were significantly related to death *When separated for region, MDS was the only diet score significantly associated with mortality in both regions

*MAI both with and without alcohol was significantly inversely associated with mortality in northern Europe

*Saturated fat intake was positively associated with mortality

*Intake of fish, fruit, fiber, cereals, alcohol and the Mediterranean components of the MAI were significantly associated with survival

*Fiber and $\mathrm{f} \& \mathrm{v}$ intakes in HDI were inversely associated with mortality
HR of diet scores for all subjects, Northern European subjects, and Southern European subjects, respectively $(\mathrm{HR}(95 \% \mathrm{CI}))$ :

MDS=.82(.75-.91), .83(.74-.93), .88(.78-.98); MDS without alcohol=.78(.71-.87), .89(.771.02), .92(.84-1.02); MAI=.83(.75-.92), .79(.74$.85), .96(.86-1.08)$; MDI without alcohol=.87(.79-.97), .83(.74-.92), .97(.86-1.10); HDI $=.89(.81-.98), .93(.85-1.02), .93(.84-1.02)$. $\mathrm{HR}(95 \% \mathrm{CI})$ for various components of each diet score in all subjects, Northern subjects, and Southern subjects, respectively: MDS fruit $=.86(.78-.94), .98(.89-1.08), .87(.77-.99)$; MDS fish=.89(.82-.97), .89(.75-1.04), .88(.78 .99). MDS grains (aka: cereal) $=.84(.77-.92)$, .90(.84-.97), 1.07(.92-1.25); MDS

alcohol=.84(.77-.92), .82(.67-.99), .77(.64-.94); MAI Mediterranean components $=.86(.79$ -

.93), .95(.85-1.07), .83(.73-.94); HDI saturated fat=1.25(1.1-1.41), .98(.61-1.56), 1.19(.95-1.48); HDI fiber $=.90(.81-.99), .86(.75-.99), .93(.83-$

1.05); HDI f\&v/potatoes=.88(.78-.99), .89(.76$1.03), .84(.68-1.05)$
Gender, baseline age, smoking activity, BMI, education, prevalence of MI, stroke, diabetes and cancer 
*Median score for each assessment

was calculated, with median or

higher indicating a healthy diet.

Lagiou et A prospective

al., 2006 analysis of

women from

Sweden

examined a

Mediterranean

diet pattern with

all-cause and

cancer mortality
Agudo et A prospective

al., 2007 analysis of adults from the EPIC-

Spain cohort

examined fruit

vegetable, and

dietary

antioxidant

intake and total

mortality.
${ }^{*} 42,237$ women, age 30-49yo

*12y follow-up

*FFQ assessed dietary intake

* Mediterranean diet score assigned based on food groups, and ranging from 0 (low adherence) to 9 points (high adherence)

*Questionnaires included lifestyle and anthropometrics (ht, wt, BMI)

* Register of Total Population records used to account for deaths

*Analysis completed for all women combined, and also for those $<40$ yo and for those $40+$ yo at baseline

*41,358 adults $(\mathrm{m}=15592, \mathrm{f}=25766)$, mean age 49.3 yo *6.5y follow-up

*Dietary history assessed intake *Interviews included lifestyle information, ht and wt measurements, and BMI calculations

*Vital stats were based on national database at the end of the follow up

*Plant foods were divided into 4 groups: legumes, potatoes and other tubers, fruit and vegetables. Total vegetables were further classified into 5 subgroups: fruiting vegetables, leafy
*Total and cancer mortality were negatively associated with MDS, but the results lacked significance in the fully adjusted model *In women aged 30-39, diet score was not associated with either cancer or total mortality

*In women $40+$ yo at baseline, an increased MDS was associated with reduction in total and cancer mortality

${ }^{*}$ Average intake of vegetables was approximately $250 \mathrm{~g}$ and fruit was more than $300 \mathrm{~g} / \mathrm{d}$

*Intake of fruiting and root vegetables and fresh fruit were inversely related to mortality

*Total vegetable consumption as a continuous variable was

associated with significant reduction in mortality

*Neither potatoes nor legumes were associated with mortality

*Vitamin E, zeaxanthin, and lutein were not associated with mortality *Vitamin C, pro-vitamin A carotenoids ( alpha- and betacarotene and beta-cryptoxanthin),
Mortality ratio $(95 \% \mathrm{CI})$ for total mortality and cancer mortality, respectively (trend per 2pt increase in score), fully adjusted: .93(.831.03), $\mathrm{p}$ for trend $=.180$, and $.89(.77-1.04), \mathrm{p}$ for trend $=.200$. Total mortality based on score (total deaths/participants, mortality ratio $(95 \% \mathrm{CI})$ in fully adjusted model: $0-3$ points $=217 / 14328,1$ (reference); $4-5$ points $=$ 245/18456, .93(.78-1.13); 6-9 points=110/9453, $.89(.77-1.04)$. Cancer mortality based on score (total deaths/participants, mortality ratio(95\%CI)): 0-3 points=106/14328, 1 (reference); $4-5$ points $=120 / 18456, .91(.69$ 1.18); 6-9 points $=54 / 9453, .80(.57-1.13)$

HR $(95 \% \mathrm{CI})$ for total vegetables and mortality by quartile $(\mathrm{Q} 1=$ reference for all categories) and continuous (HR-C, 95\% CI): $\mathrm{Q} 2=.75(.59-.96), \mathrm{Q} 3=.81(.64-1.03), \mathrm{Q} 4=.84(.66-$ 1.06), $\mathrm{p}$ for trend $=.23$, HR-C=.91(.83-.99). HR $(95 \% \mathrm{CI})$ for fruiting vegetables and

mortality by quartile and continuous (HR-C 95\%I): Q2=.93(.74-1.17), Q3=.78(.61-.99), $\mathrm{Q} 4=.77(.60-.98), \mathrm{p}$ for trend $=.015, \mathrm{HR}-$ $\mathrm{C}=.93(.87-.98)$. HR (95\%CI) for root vegetables and mortality by quartile and continuous (HR-C, 95\%CI): Q2=.82(.65-1.1), $\mathrm{Q} 3=.80(.63-1.0), \mathrm{Q} 4=.72(.56-.91), \mathrm{p}$ for trend=.006, HR-C=.94(.89-1.0). HR $(95 \% \mathrm{CI})$ for total fruit and mortality by quartile and continuous (HR-C, 95\%CI): Q2=.83(.66-1.05), $\mathrm{Q} 3=.74(.58-.94), \mathrm{Q} 4=.82(.64-1.04)$, $\mathrm{p}$ for
Age, ht, BMI, smoking status, activity level, education, energy intake, potato intake, egg intake, PUFA intake, sweets intake, and nonalcoholic beverage intake

Age, sex, education, activity, smoking, BMI, alcohol, and total energy intake 
vegetables, root vegetables, cabbage family, and onion and garlic

*The total fruit group included seeds, nuts and olives

*Antioxidant content for foods was obtained from a database, including vitamins $C \& E$, betaand alpha-carotene, lycopene, lutein, beta-cryptoxanthin,

zeaxanthin, and total antioxidant capacity (TAC)

*All variables were classified by quartile of intake lycopene and total carotenoids were inversely related to risk of death

*All four measures of TAC from plant foods were associated with increased survival rates *Lycopene had a linear relationship with mortality, * Mortality was reduced as fresh fruit and vegetable intake was increased trend=.061, HR-C=.96(.92-1.0). HR (95\%CI)

for fresh fruit and mortality by quartile and continuous (HR-C, 95\%CI): Q2=.87(.69-1.09) $\mathrm{Q} 3=.77(.60-.97), \mathrm{Q} 4=.79(.62-1.0)$, $\mathrm{p}$ for trend $=.029$, HR-C $=.96(.93-1.0)$. HR $(95 \% \mathrm{CI})$ for vitamin $\mathrm{C}$ and mortality by quartile and for continuous (HR-C, 95\%CI): Q2=.72(.57$.91), \mathrm{Q} 3=.65(.51-.83), \mathrm{Q} 4=.74(.58-.94), \mathrm{p}$ for trend=.009, HR-C=.87(.78-.96). HR $(95 \% \mathrm{CI})$ for beta-carotene and mortality by quartile and for continuous (HR-C, 95\%CI): $\mathrm{Q} 2=.76(.60-.96), \mathrm{Q}=.72(.56-.92), \mathrm{Q} 4=.74(.58-$ $.95), \mathrm{p}$ for trend $=.022$, HR-C $=.89(.80-.98)$. HR (95\% CI) for alpha-carotene and mortality by quartile and for continuous (HR-C, 95\% CI): $\mathrm{Q} 2=.86(.68-1.08), \mathrm{Q} 3=.84(.67-1.06)$, $\mathrm{Q} 4=.75(.59-.96), \mathrm{p}$ for trend $=.023, \mathrm{HR}-$ $\mathrm{C}=.95(.91-1.0)$. HR (95\%CI) for betacryptoxanthin and mortality by quartile and for continuous (HR-C, 95\%CI): Q2= .73(.57.92), Q3=.77(.61-.98), Q4=.75(.59-.95), $\mathrm{p}$ for trend $=.034, \mathrm{HR}-\mathrm{C}=.94(.90-.99)$. HR $(95 \% \mathrm{CI})$ for lycopene and mortality by quartile and for continuous (HR-C, 95\%CI): Q2=.79(.63.99), $\mathrm{Q} 3=.76(.60-.96), \mathrm{Q} 4=.65(.51-.84), \mathrm{p}$ for trend=.001, HR-C=.93(.89-.97). HR $(95 \% \mathrm{CI})$ for total carotenoids and mortality by quartile and for continuous (HR-C, 95\%CI): $\mathrm{Q} 2=.74(.59-.93), \mathrm{Q} 3=.70(.55-.89), \mathrm{Q} 4=.69(.55-$ $.88), \mathrm{p}$ for trend $=.003$, HR-C $=.85(.76-.94)$. $\mathrm{HR}(95 \% \mathrm{CI})$ for lycopene and association with mortality by quartile and for continuous models, reduced model analysis: $\mathrm{Q} 2=.82(.65-1.03), \mathrm{Q} 3=.81(.64-1.02)$,

$\mathrm{Q} 4=.70(.54-.91)$, $\mathrm{p}$ for trend $=.005$, HR$\mathrm{C}=.95(.90-.99)$ 


\section{A prospective} analysis of

European adults from the EPIC-

Elderly Study

examined an a

posteriori dietary

pattern that was

primarily plant-

based, and its

association to all-

cause mortality

Anderson A prospective

et al., 2011 analysis of subjects from the

Health, Aging and Body

Composition

Study examined

dietary patterns

and all-cause

mortality.
*74,607 adults, $60+y o$

*FFQ assessed dietary intake

${ }^{*} \mathrm{Ht}$, wt, and waist and hip

circumference were measured

* Follow-up with subjects and with the population mortality registries confirmed vital status *Plant-based diet included positive scoring of vegetables and vegetable oils, pasta/rice/other grains, fruit, and legumes while non-alcoholic beverages, potatoes, and margarine resulted in negative scores

* Subjects were divided into tertiles according to plant-based diet scores, with tertile 1 being the least plant-based and tertile 3 being the most plant-based * Relationships between diet and mortality were assessed for all countries and also within country

*2,582 adults, 70-79yo

*10y follow-up

${ }^{*} \mathrm{FFQ}$ assessed dietary intake

*Interviews included behavior, health status, socio-demographics, body composition, weight-related health conditions and physical function at baseline and at followups

*Lab assessments throughout the $10 \mathrm{y}$ period included fasting glucose and insulin, serum folate homocysteine, vitamin B-12, and holotranscobalamin (a marker of B-12), and antioxidant status (vit
*Deaths decreased as tertile scores increased

* The plant-based diet was associated with reduced overall mortality

*Subjects in the third tertile had an $11 \%$ reduced rate and those in the second had a $10 \%$ reduced rate of mortality, compared to those in the lowest tertile

* Most countries had similar results, but this association between plant-based diet and mortality was not present in the UK or in Germany, where a high proportion of subjects fell into the second tertile
*The HF group had higher HEI and more years of healthy life than the other 5 groups

*HF had the lowest mortality rate $(21 \%)$, with significant differences between both the HFDP (34\%) and SD (32\%) after all adjustments * Risk of mortality between HF and MFFA was significant when adjusted only for gender, age and race
Mortality ratio $(95 \% \mathrm{CI})$ over all countries: fixed effects 2 nd tertile $=.93(.86-1.0)$; fixed effects 3rd tertile $=.92(.79-1.06)$; fixed effect per 1SD increment $=.90(.85-.96)$. Random effects 2nd tertile $=.90(.84-.98)$; random effects 3rd tertile $=.89(.79-.99)$; random effect per 1SD increment=.86(.77-.95); $\mathrm{p}$-value for heterogeneity 2 nd tertile $=.502 ; \mathrm{p}$-value $3 \mathrm{rd}$ tertile=.124; $\mathrm{p}$-value $1 \mathrm{SD}=.06$
Age, gender, selfreported diabetes status, education, activity level, smoking, WHR $\mathrm{BMI}$ and total energy intake
Fully adjusted mortality risk $(95 \% \mathrm{CI})$ : $\mathrm{HF}=1.0$; HFDP=1.4 (1.04-1.88); MFFA=1.21(.92-1.60); $\mathrm{BC}=1.16(.86-1.56)$; RG=1.08(.80-1.45); $\mathrm{SD}=1.37$ (1.02-1.86).

Partially adjusted mortality risk $(95 \% \mathrm{CI})$ :

$\mathrm{HF}=1 ; \mathrm{HFDP}=1.59(1.19-2.14) ; \mathrm{MFF}=1.39$ (1.06-.182); $\mathrm{BC}=1.25(.93-1.69) ; \mathrm{RG}=1.32(.99$ 1.76); $\mathrm{SD}=1.52(1.13-2.04)$
Fully adjusted: gender, age, race, clinical site, education level, physical activity level, smoking, and total energy intake. Partially adjusted model gender, age and race only 

C, beta-carotene, and alpha-
tocopherol)
${ }^{*}$ General health was reported
every 6 months via interview and
healthy years of life were
calculated from baseline through
year 9
*Subjects were divided into 1 of 6
dietary patterns(Healthy Foods
(HF), High-Fat Dairy Products
(HFDP), Meat, Fried Foods and
Alcohol (MFFA), Breakfast Cereal
(BC), Refined Grains (RG), and
Sweets and Desserts (SD)
*Survival rates, QOL and nutrition
status were assessed based on
dietary patterns
*HEI was assigned to each subject

Note: $\mathrm{WHO}=$ World Health Organization, $\mathrm{HDL}=$ High density lipoprotein, $\mathrm{PUFA}=$ poly-unsaturated fatty acid, $\mathrm{f} \& \mathrm{v}=\mathrm{fruits}$ and vegetables, $\mathrm{SD}=\mathrm{standard}$ deviation, $\mathrm{RR}=\mathrm{relative}$ risk, MONICA=Monitoring of trends and determinants in cardiovascular disease, SENECA=Survey in Europe on nutrition and the elderly; a concerted action, $\mathrm{Ht}=$ height, $\mathrm{Wt}=\mathrm{weight}$ BMI=body mass index, HRR=hazard rate ratio, HRRE=hazard rate ratio estimates, CI=confidence interval, NHS=Nurses Health Study, CHD=coronary heart disease, $\mathrm{CVD}=$ cardiovascular disease, $\mathrm{MI}=$ myocardial infarction, $\mathrm{HTN}=$ hypertension, $\mathrm{ARIC}=$ Atherosclerosis Risk in Communities, WHR=waist-hip-ratio, $\mathrm{SBP}=$ systolic blood pressure, HDL=high-density lipoprotein, LDL=low-density lipoprotein, $C A D=$ coronary artery disease, HR=hazard ratio, HDI=Healthy Diet Indicator, MDI= Mediterranean Adequacy Index, MDS=Mediterranean Diet Score, HALE=Health Aging, a longitudinal study in Europe, EPIC=European Prospective Investigation into Cancer and Nutrition, HEI=Healthy eating index, QOL=quality of life

Table E - Spiritual Wellness: The effect of faith-based healthy lifestyle interventions on dietary intake in older adults.

\begin{tabular}{|c|c|c|c|c|c|}
\hline $\begin{array}{c}\text { Author \& } \\
\text { year }\end{array}$ & Objective & Design & Results & Statistics & $\begin{array}{l}\text { Confounders } \\
\text { adjusted for }\end{array}$ \\
\hline $\begin{array}{l}\text { Resnicow } \\
\text { et al., } 2004\end{array}$ & $\begin{array}{l}\text { Body \& Soul - A } \\
\text { randomized } \\
\text { controlled trial } \\
\text { examining f\&v } \\
\text { intake change } \\
\text { from baseline to }\end{array}$ & $\begin{array}{l}{ }^{*} 854 \text { adults, mean age } 51 y o \\
{ }^{*} 15 \text { congregations ( } 8 \text { intervention, } \\
7 \text { control) } \\
{ }^{*} 6 \text { mo church-wide intervention } \\
\text { plus optional individual } \\
\text { counseling available }\end{array}$ & $\begin{array}{l}\text { *Similar retention rates between } \\
\text { intervention }(85 \%) \text { and control } \\
(83 \%) \text { churches. } \\
\text { *Significant increased intake of } \\
\text { f\&v in intervention vs. control } \\
\text { group subjects }\end{array}$ & $\begin{array}{l}\text { Effect size of significant post-test difference } \\
\text { between intervention and control subjects: } 2 \text { - } \\
\text { item } f \& v \text { measure }=.39 ; 17 \text {-item } \mathrm{f} \& \mathrm{v} \\
\text { intake }=.18 ; 1 \text {-item fruit intake }=.46 ; 1 \text {-item } \\
\text { vegetable intake }=.18 ; \% \text { energy from fat }=.26 \text {; } \\
\text { autonomous motivation }=.21 \text {; controlled }\end{array}$ & $\begin{array}{l}\text { Baseline value, } \\
\text { age, gender, } \\
\text { education, } \\
\text { income and } \\
\text { marital status }\end{array}$ \\
\hline
\end{tabular}


a faith-based

dietary

intervention.

${ }^{*} \mathrm{FFQ}$ and other questionnaires assessed diet, motivation, and program satisfaction

Campbell Further analysis

et al., 2007 of Body \& Soul results to

determine effectiveness of each program component.
Bopp et

al., 2009
A nested quasiexperimental

design (8 Steps to Fitness),

examining physical activity, psychological and health outcomes, and

diet in a faithbased

intervention.
*526 adults, mean age 50.6, from the Body \& Soul intervention *Questionnaires for attendance, exposure to various program components, and interaction with volunteers
*Improved post-test fat intake, autonomous motivation for $\mathrm{f} \& \mathrm{v}$ intake, controlled response for $\mathrm{f} \& \mathrm{v}$ intake, self-efficacy of f\&v intake, and social support to eat more $f \& v$

*Increased produce consumption and decreased fat intake were associated with the educational materials and attending the kickoff event

*Attendance at other events was related to higher f\&v intake * MI calls alone had no positive impact on diet, but higher f\&v intake for those who received MI and spoke as much or more than the advisor

*Better scores on low-fat food preparation in those who did not receive MI

*Improvements in both f\&v intake and in social support were related to overall perceived quality of MI advisor's efforts

*Attrition rate: control group: 58\% (controls) and 36\% (intervention)

*6-month follow up: greater improvements in the intervention group than the control group for depression, enjoyment of physical activity, hip circumference and SBP

*Dietary habits were not positively impacted response=.33; self-efficacy $=.22$; social support $=.39$

Difference in produce intake in relation to education materials and kick-off attendance $=0.92$, $\mathrm{p}$-value $=.008$ and $=0.82$, $\mathrm{p}$-value $=.002$, respectively; difference in fat intake in relation to education materials and kick-off attendance $=-2.20, p$-value $=.002$ and $=-0.65$, $\mathrm{p}$-value $=.13$, respectively. Difference in produce intake as related to attending project events aside from kick-off $=.58, \mathrm{p}$ value-.004 and 1.02, p-value-.045 for the 2 item and 17-item measures, respectively. Self-efficacy difference associated with educational materials and attending project events/classes $=0.24$, $\mathrm{p}$-value $=.012$ and $=0.13$, $\mathrm{p}$-value $=0.27$, respectively. Low-fat food preparations differences related to not receiving $\mathrm{MI}$ calls $=-0.07, \mathrm{p}$-value $=.04$

Effect size for social support from church members at 6 mos $=0.59$, for hip circumference and systolic blood pressure from baseline to $6 \mathrm{mos}=-0.27$ and -0.40 , respectively, and for physical activity from baseline to $6 \mathrm{mos}=0.58$ assessment, height, weight, waist, hip, WHR, fasting blood glucose, and resting BP ${ }^{*}$ Questionnaires to assess social support, self-efficacy, enjoyment depression, activity level, dietary fat and cholesterol
Age and gender

For health: age and education; psychosocial outcomes: age, BMI, education; physical activity: age, BMI,

education level; and diet: age,

BMI, education 
Baruth et A cross-sectional al., 2011 analysis of data from the Faith, Activity, and Nutrition (FAN) intervention,

examining

church support and the effects on healthy eating behaviors.

Wilcox et A randomized al., 2013 controlled trial using a communitybased participatory approach for physical activity and diet.

\section{Baruth et Statistical} al., 2013 analysis of FAN pre/post test results evaluated

how many subjects improved physical activity
*See Wilcox, 2013 for intervention details

*Analysis: Questionnaires assessed 3 components of perceived church support: written informational support, spoken support, and instrumental support

${ }^{*}$ Total church support (all 3 components) significantly associated with improved diet, including more fruits, vegetables and fiber and less fat intake *Improved dietary behaviors positively associated with written information

*Perceived spoken support associated with more fruit,

vegetable and fiber but no impact on dietary fat

*Instrumental support not associated with change in $\mathrm{f} \& \mathrm{v}$ intake

*1,257 adults, mean age 54yo *15-month RCT (organizational and environmental changes) ${ }^{*}$ Control: same intervention, 15 months later

*Baseline and 15-month follow-up measurements: Height, weight, BP, BMI, and self-reported information on physical activity, $\& v$ intake, fat and fiber related

behaviors, and training evaluations

*360 participants from FAN intervention (see Wilcox, 2013)

* Participants successfully changing each individual behavior, total number of behaviors changed, each combination of behavior changes, and potential relationship between behavior changes

${ }^{*} 62 \%$ of all subjects completed the program

* $\mathrm{f} \& \mathrm{v}$ consumption was higher in intervention compared to control subjects

${ }^{*}$ No differences in any other variables

*Behavior changes in order from most common to least common: decreased fat-related behaviors $(43 \%)$, improved fiber-related behaviors (42\%), increased physical activity (36\%) and increased $\mathrm{f} \& \mathrm{v}$ intake (33\%). * $81 \%$ of participants changed at least one of the four behaviors.
Total church support and dietary practices 0.05 (p-value $=.002$ ), written information and dietary practices $=.05(\mathrm{p}=.001)$, spoken support and dietary practices $=.003(\mathrm{p}=.004), \quad$ and BMI and instrumental support and dietary practices $=.01(\mathrm{p}=.95)$. Statistical significance was accepted at $\mathrm{p}<0.05$
Fruit and vegetable intake for control (mean=3.25 (SE=0.20) vs. intervention mean=3.89 (SE=0.17), d=0.17, $\mathrm{F}=5.17$, $\mathrm{p}-$ value $=0.03$

See outcomes and percentages in Results section.
Pre-intervention

values of

outcomes of

interest, church

clustering or

church

congregation,

church wave and

size, and

participant age

education level

and gender

Church

clustering, age,

gender,

education level,

hurch wave, and

church size 
and diet

behaviors.

Thomson Analysis of et al., 2014 results from the

Delta Body \& Soul faith-based healthy lifestyle intervention examined psychosocial constructs and associations with change in diet and activity after the intervention
*403 adults, mean age 50 years *6-month quasi-experimental design (Intervention: monthly sessions plus church-wide changes. Control: bi-monthly newsletters)

* Subjects divided into control $(\mathrm{n}=174), \mathrm{LAI},(\mathrm{n}=89)$, and HAI $(\mathrm{n}=77)$.

* Questionnaires for sociodemographics, lifestyle, activity level, and motivation

*FFQ to assess diet, and HEI-2005 score calculated accordingly ${ }^{*}$ Height, weight, BMI
* Related behaviors included fat and fiber behaviors, increased activity and increased produce consumption, and improved fatrelated behaviors and improve fiber-related behaviors.

*Improved diet quality on all six components of HEI-2005

*Improved self-efficacy for diet in HAI subjects

${ }^{*}$ No significant change in diet overall

*Increased social support for sugary drinks and whole grains in LAI subjects

*Increased fruit intake and social support for sugary drinks in control subjects

*Social support and decisional balance (pro) were positive predictors of diet quality change for SoFAAS and total vegetable intake
Change in diet (Mean(SD)), HEI-2005 total fruit: control=.3(1.8); $\mathrm{LAI}=.4(1.7)$;

HAI=.7(1.6), $p=n s$. Change in diet, HEI-2005 SoFAAS: control=3.4(9.8); LAI=-.7(5.1); HAI=2.1(4.1), $p=.026$. Change in diet, HEI2005 Total score: control=3.4(9.6); $\mathrm{LAI}=.2(9.7) ; \mathrm{HAI}=6.1(8.8), \mathrm{p}=.003$.

Psychosocial changes, SS for sugarsweetened drinks: control=-.3(3.4); $\mathrm{LAI}=.12(3.4)$; HAI $=.7(3.6), \mathrm{p}=.003$. Dietary changes predicted by psychosocial constructs (b(SEM)), HEI-2005: SS total vegetables=.03(.016); DB SoFAAS=.42(.12); SS Total Score $=.29(.121)$. Dietary change in FFQ (servings) predicted by psychosocial constructs (b(SEM)): SS total vegetables $=.03(.010)$; DB (pro) whole grains $=.03(.014)$; SE sugary drinks $=-.05(.016)$; $\mathrm{SE}$ total energy $=-85.2(25.64)$

Note: BP=blood pressure, WHR=waist-hip-ratio, BMI=body mass index, SBP=systolic blood pressure, DBP=diastolic blood pressure, HEI-2005=Healthy Eating Index 2005, $\mathrm{FFQ}=$ food frequency questionnaire, $\mathrm{NCI}=$ National Cancer Institute, $\mathrm{TSRQ}=$ treatment self regulation questionnaire, $\mathrm{f} \& \mathrm{v}=$ fruit and vegetable, $\mathrm{ANCOVA}=\mathrm{Analysis}$ of covariance, $\mathrm{OR}=$ odds ratio, DASH=Dietary Approaches to Stop Hypertension, SoFAAS=solid fats and added sugars, MI=motivational interview, RCT=randomized controlled trial, FAN=Faith, Activity and Nutrition, DB=decisional balance, SS=social support, , LAI=low-attendance intervention, HAI=high-attendance intervention, HEI=Healthy Eating Index, $\mathrm{SEM}=$ standard error of the mean, $\mathrm{SE}=$ self efficacy, $\mathrm{SD}=$ standard deviation, $\mathrm{SE}=$ standard error

Table F - Social wellness: The effects of social interactions on dietary intake in older adults

\begin{tabular}{|c|c|c|c|c|c|}
\hline $\begin{array}{c}\text { Author \& } \\
\text { year }\end{array}$ & Objective & Design & Results & Statistics & $\begin{array}{l}\text { Confounders } \\
\text { adjusted for }\end{array}$ \\
\hline $\begin{array}{l}\text { de Castro, } \\
1994\end{array}$ & $\begin{array}{l}\text { A cross-sectional } \\
\text { analysis }\end{array}$ & $\begin{array}{l}\text { *515 adults ( } \mathrm{m}=276, \mathrm{f}=239) \text {, mean } \\
\text { age } 41.9 \text { yo (range } 29-55 \text { yo) }\end{array}$ & $\begin{array}{l}{ }^{*} \text { Meals eaten alone were smallest } \\
\text { and shortest duration }\end{array}$ & $\begin{array}{l}\text { Mean meal size (kcal) related to companion } \\
\text { type: spouse } F(2,590)=145.60 \text {, family } F(2 \text {, }\end{array}$ & None provided \\
\hline
\end{tabular}


examined the relationship

between dietary intake and presence of different dining companions.

An observational study of

Canadian adults

examined

predictors of

dietary intakes in

a population

dependent on

others for ADLs

and often

diagnosed with

at least one

chronic disease.

$\begin{array}{lll}\text { de Castro, } & \begin{array}{l}\text { An observational } \\ \text { study examined }\end{array} & \text { *762 adults }(\mathrm{m}=348, \mathrm{f}=414), 20 \text { - } \\ 2002 & \text { yo }\end{array}$

the effects of *7d food diary assessed intake,

dining companions, meal

duration, time of day, and hunger ratings

*Ht and wt measured and BMI calculated, and seven-day food diary was acquired

*Data was broken down into 5 companion types: family, friend, spouse, coworker, and other

*145 adults, $(\mathrm{m}=42, \mathrm{f}=103)$, mean age 78.8yo

${ }^{*}$ Three separate $24 \mathrm{~h}$ dietary recalls assessed dietary intake

*Structured interview for diet stressful events, sociodemographics, health history, current health and medications, lifestyle, and self-reported weight conducted

${ }^{*} \mathrm{Ht}$ and wt measured and BMI calculated habits, social network, recent
*Meals eaten with spouse, family or friends were significantly larger than with other companions

* Meals eaten with coworkers were smaller than with other dining companions

* Meal size did not change for male subjects dining with other men

* Meal size increased for female subjects dining with men

*Significant positive correlation between total number of

companions present at a meal and the amount of calories consumed * Meals with family and spouse were larger and eaten more quickly while

*Meals with friends were large and eaten more slowly

*Over half of subjects reported feeling lonely most of the time

*Very few subjects participated in clubs or senior centers

*Overall saturated fat intake was high (up to $13 \%$ of total energy)

*PUFA intake was low

*Only 5 subjects total reported participating in communal meals *Stressful events were associated with decreased protein intake in men

*Having friends was associated with increased total energy intake in all subjects

*Mean number of people present at meals was lowest for elderly and highest for middle-aged
726)=99.05, friend $\mathrm{F}(2,646)=114.47$, coworker $F(2,538)=101.88$, others $F(2$,

156) $=19.96$. Meal size of meals eaten with any other companion type vs. eaten alone, respectively: spouse $\mathrm{t}(295)=19.96$ vs. 8.81 , family $\mathrm{t}(363)=12.26$ vs. 12.83 , friend $t(323)=13.33$ vs. 13.54 , coworker $t(269)=6.18$ vs. 18.13 , and others $t(78)=3.71$ vs. 8.95 . Females eating with males compared to females eating with other females:

$t(162)=2.92$

Frequency of social contacts in men and women, respectively (\%): $>1 \mathrm{x} / \mathrm{wk}=83$ and 80 $1 \mathrm{x} / \mathrm{wk}=10$ and $11 ; \leq 1 \mathrm{x} / \mathrm{month}=7$ and 10 .

Gender, food prep/purchase/co nsumption patterns

Subjects reporting having friends, men and women respectively (\%): 74 and 82 .

Company at mealtime and in men and women, respectively $(\%):<5 x /$ wk $=69$ and 51 $\geq 5 \mathrm{x} / \mathrm{wk}=31$ and 49 . Stress level as predictor of protein intake (estimated regression coefficient (SE): -3.29(1.61), $\mathrm{p}<.05$.

None provided - see illustrations in original source for visual interpretation of study results. 
various non-

physiological

factors on dietary

intake based on

age.

Sahyoun A cross-sectional

\& Zhang, study of

2005

NHANES III
*Subjects divided based on age into young adults (20-34yo,

$\mathrm{n}=325)$, middle-aged (35-49yo, $\mathrm{n}=292)$, older adults (50-64yo, $\mathrm{n}=99)$, and elderly (65+ yo, $\mathrm{n}=46$ )

*7d food diary assessed intake

*Self-reported ratings of

depression, anxiety, attractiveness,

hunger and thirst were recorded

*Socio-demographic, health, and

lifestyle information were

collected

*Three-Factor Eating

Questionnaire measured dietary

restraint, hunger and dis-

inhibition

3,194 adults ( $\mathrm{m}=1579, \mathrm{f}=1615)$

mean age $73 y o$

participants,

aged 65yo or

older, examined

living

arrangements

and social contact

as they relate to

HEI scores.
政

*HEI assessed caloric intake, total

nutrient intake, and vitamins E, C,

A, folate and carotenes

*Social contact (independent

variable) assessed based on 5

categories: phone contact with

family/friends, getting together

with friends and relatives, visits

with neighbors (later combined

into the same category as getting

together with friends/family),

attendance at church/religious

services, and

membership/attendance at club meetings

*Total scores of 1 (zero to one

social contact) to four (maximum

number of social contacts)

assigned for each category
*All age groups demonstrated a significant positive correlation

between meal size and number of people present

*All subjects ate more food when dining at restaurants compared to at home

* Women with fewer social contacts consumed fewer calories and had lower intakes of vitamins $\mathrm{A}$ and $\mathrm{C}$ and folate (when

controlling for total caloric intake, only vitamin $\mathrm{C}$ maintained

statistical significance)

*People reporting less socializing

were more likely to have lower

HEI scores

* Strong relationship between

social contact and HEI score even

after adjusting for ethnicity and

age (relationship was weaker

when adjusting for smoking,

poverty index, functional status,

education, living arrangement,

self-reported health, dental health,

and caloric intake)

${ }^{*}$ Fruits intake and diet variety

somewhat significantly associated
Relationship between social contact and total Age, race, caloric intake in women (LSM(SE)): 0-1

ethnicity,

contacts: 1366 (86), p-value=.017; 2 contacts: smoking status,

$1435(38), \mathrm{p}=027 \cdot 3$ contacts: $1437(33), \mathrm{p}=016$

4 contacts: $1575(\mathrm{SE}=39)$, p-value $=\mathrm{NA}$

(reference category). Relationship between

social contact and total caloric intake in men

(LSM(SE)): 0-1 contacts: 1967(81), p-

value $=873 ; 2$ contacts: $1990(46), p=.905 ; 3$

contacts: $2004(38), \mathrm{p}=.769$; 4 contacts:

982(62), p-value=NA (reference category)

Relationship between social contacts and

HEI score in women (LSM(SE)): 0-1 contact:

67.1(1.7), p-value $=.037 ; 2$ contacts: $69.7(1.0)$,

$\mathrm{p}=.362 ; 3$ contacts: $70.6(.7), \mathrm{p}=.745 ; 4$ contacts

71.0(.7), $\mathrm{p}=\mathrm{NA}$ (reference category).

Relationship between social contacts and

HEI score in men (LSM(SE)): 0-1 contact:

64.9(1.6), $\mathrm{p}=.154 ; 2$ contacts: $65.1(.6), \mathrm{p}=.032 ; 3$

contacts: $67.1(.9), \mathrm{p}=.438 ; 4$ contacts: $67.8(1.1)$, $\mathrm{p}=\mathrm{NA}$ (reference category). poverty income

ratio, education

physical

functioning

living

arrangement,

self-reported

health condition,

and dental

health. Total

caloric intake

was also

considered a

confounder, in

addition to being

an outcome

variable. 
Locher et al., 2005

An observational study examined

the effects of cohabitation and presence of

dining companions on caloric intake.

Cohen-

Mansfield

social, temporal environmental

and situational conditions and dietary intake. with social contact when all

confounders were factored in

* Mean energy intake increased as social contact increased in women only

*Living arrangement not associated with dietary intake

*Limited social contact

significantly associated with lower

HEI scores and fewer calories consumed

*More women than men lived alone (39\% vs. $13.2 \%$, respectively)

*50 adults $(\mathrm{m}=18, \mathrm{f}=32)$ mean age 77 yo

*Three separate $24 \mathrm{~h}$ dietary recalls assessed dietary intake

*Structured interview assessed eating behavior and social factors

${ }^{*}$ Average caloric intake was 1,305 $\mathrm{kcal} / \mathrm{d}$

${ }^{*}$ Caloric intake was higher when meals were eaten with others (average $114 \mathrm{kcal} / \mathrm{meal}$ increase)

*58 adults, mean age 78 to 84 years $\quad{ }^{*} \mathrm{RH}$ subjects had the option to *Subjects divided into 2 groups: Private housing subjects $(\mathrm{PH}$, $\mathrm{n}=40$ ) and retirement community subjects (RH, $\mathrm{n}=18$ ) *SHAPE questionnaire administered by trained staff evaluated diet and behaviors
Caloric intake per meal while dining alone (mean (SD)): breakfast=384.3 (195.2),

lunch=342.5(243.4), dinner=363.1(185.6), snack=152.0(126.3). Caloric intake per meal with others present (mean(SD)):

breakfast=424.1 (180.9), lunch=440.5(220.6), dinner $=454.0(241.2)$, snack $=169.8(104.8)$

Subjects watching TV during meals for $\mathrm{PH}$ and $\mathrm{RH}$, respectively (\%): breakfast $=24$ and 50 , lunch $=16$ and 39 , dinner $=55$ and 0 . Subjects socializing during meals for $\mathrm{PH}$ and $\mathrm{RH}$, respectively (\%): breakfast $=10$ and 0 , lunch $=13$ and 11 , dinner $=29$ and 72 . Subjects eating alone for $\mathrm{PH}$ and $\mathrm{RH}$, respectively $(\%)$ : breakfast $=32$ and 72 , lunch $=26$ and 67 , dinner $=5$ and 6 . Subjects eating with a spouse for $\mathrm{PH}$ and $\mathrm{RH}$, respectively (\%): breakfast $=60$ and 22 , lunch $=55$ and 28 , dinner $=92$ and 22. Subjects eating with a friend(s) for $\mathrm{PH}$ and $\mathrm{RH}$, respectively (\%): breakfast $=3$ and 0 , lunch $=5$ and 0 , dinner $=10$ and 67. Importance of dining companion at meal for $\mathrm{PH}$ and $\mathrm{RH}$, respectively (mean): breakfast $=2.13$ and 1.86 , lunch $=2.36$ and 1.93 , dinner=2.87 and 2.57 .
'Pubjects were responsible for

${ }^{*} \mathrm{RH}$ subjects were older and more

likely to be single than $\mathrm{PH}$ subjects

subjects

* $\mathrm{PH}$ residents socialize more

dinner than $\mathrm{PH}$

*PH subjects dined with spouses

more frequently than $\mathrm{RH}$

${ }^{*} \mathrm{RH}$ subjects dined with friends

more than $\mathrm{PH}$ 
Conklin et A study of

al., 2014 subjects from the EPIC UK cohort examined the association between social relationships and healthful dietary behaviors.
*9,580 adults $(\mathrm{m}=4311, \mathrm{f}=5269)$, mean age 62 yo

${ }^{*}$ FFQ assessed dietary intake ${ }^{*}$ Health and Life Experiences Questionnaire assessed diet and lifestyle

*A higher score in variety of fruits and in variety of vegetables is associated with better health outcomes

*Marital status, living arrangement (shared vs. alone), friend contact and family contact were assessed in regards to fruit and vegetable consumption
*Dinner was rated the most

important meal for all subjects

*Men's diets more negatively affected than women in regards to lone-living, un-partnered status and limited friend contact

*Widowed men and women had lower vegetable scores compared to partnered people

*Lone-living men had lower vegetable intake than lone-living women

*Un-partnered older adults with frequent friend contact had higher f\&v scores than those with infrequent friend contacts *Lone-living people had lower fruit and lower vegetable scores than shared living people *Weekly family contact associated with the most positive association in vegetable variety in women
Vegetable variety in partnered men compared to married men: -2.17 unit difference, $\mathrm{p}<.001$. Vegetable variety in widowed women compared to partnered women: -.79 unit difference, $p=.005$. Mean vegetable variety score in all subjects by frequency of friend contact (mean score(SD)): Daily=16.7(4.1),

Weekly=16.5(3.9), Monthly=16.2(3.9), Rare/never=15.2(4.3). Mean vegetable variety score in all subjects by frequency of family contact (mean score(SD)): Daily=16.1(4.0), Weekly=16.5(4.0), Monthly=16.0(4.1),

Rare/never=15.6(4.1)

Mean fruit variety score by living arrangements (mean score(SD)):

Shared $=7.3(2.4)$, alone=7.2(2.5). Mean vegetable variety score by living arrangement (mean score(SD)):

Shared=16.4(3.9), alone=15.4(4.3). Mean fruit variety score by marital status (mean score (SD)): partnered $=7.3(2.4)$, single $=6.9(2.6)$, widowed $=7.4(2.4)$

divorced/separated=7.4(2.6). Mean vegetable variety score by marital status (mean score (SD)): partnered=16.4(3.9), single=14.3(4.6), widowed=15.1(4.3),

divorced/separated $=16.4(4.1)$

Note: $\mathrm{Ht}=\mathrm{ht}$, wt=wt, BMI=body mass index, PUFA=poly-unsaturated fatty acids, ADL=activities of daily living, SE=standard error, HEI= Healthy Eating Index, NHANES=National Health and Nutrition Examination Survey, LSM=Least square means, SD=standard deviation, SHAPE= Self-maintenance Habits and Preferences in Elderly, EPIC UK=European Prospective Investigation of Cancer United Kingdom, FFQ=food frequency questionnaire, $f \& v=$ fruits and vegetables 